\title{
Long-Lasting Electrophysiological After-Effects of High-Frequency Stimulation in the Globus Pallidus: Human and Rodent Slice Studies
}

\author{
Feng Luo, Linda H. Kim, Philippe Magown, M. Sohail Noor, and Zelma H.T. Kiss \\ Department of Clinical Neurosciences and Hotchkiss Brain Institute, Cumming School of Medicine, University of Calgary, Calgary, Alberta T2N 4N1, \\ Canada
}

Deep-brain stimulation (DBS) of the globus pallidus pars interna (GPi) is a highly effective therapy for movement disorders, yet its mechanism of action remains controversial. Inhibition of local neurons because of release of GABA from afferents to the GPi is a proposed mechanism in patients. Yet, high-frequency stimulation (HFS) produces prolonged membrane depolarization mediated by cholinergic neurotransmission in endopeduncular nucleus (EP, GPi equivalent in rodent) neurons. We applied HFS while recording neuronal firing from an adjacent electrode during microelectrode mapping of GPi in awake patients (both male and female) with Parkinson disease (PD) and dystonia. Aside from after-suppression and no change in neuronal firing, high-frequency microstimulation induced after-facilitation in 38\% (26/69) of GPi neurons. In neurons displaying after-facilitation, 10 s HFS led to an immediate decrease of bursting in PD, but not dystonia patients. Moreover, the changes of bursting patterns in neurons with after-suppression or no change after HFS, were similar in both patient groups. To explore the mechanisms responsible, we applied HFS in EP brain slices from rats of either sex. As in humans, HFS in EP induced two subtypes of after-excitation: excitation or excitation with late inhibition. Pharmacological experiments determined that the excitation subtype, induced by lower charge density, was dependent on glutamatergic transmission. HFS with higher charge density induced excitation with late inhibition, which involved cholinergic modulation. Therefore HFS with different charge density may affect the local neurons through multiple synaptic mechanisms. The cholinergic system plays a role in mediating the after-facilitatory effects in GPi neurons, and because of their modulatory nature, may provide a basis for both the immediate and delayed effects of GPi-DBS. We propose a new model to explain the mechanisms of DBS in GPi.

Key words: cholinergic; DBS; GPi; human; microstimulation

\section{Significance Statement}

Deep-brain stimulation (DBS) in the globus pallidus pars interna (GPi) improves Parkinson disease (PD) and dystonia, yet its mechanisms in GPi remain controversial. Inhibition has been previously described and thought to indicate activation of GABAergic synaptic terminals, which dominate in GPi. Here we report that $10 \mathrm{~s}$ high-frequency microstimulation induced afterfacilitation of neural firing in a substantial proportion of GPi neurons in humans. The neurons with after-facilitation, also immediately reduced their bursting activities after high-frequency stimulation in PD, but not dystonia patients. Based on these data and further animal experiments, a mechanistic hypothesis involving glutamatergic, GABAergic, and cholinergic synaptic transmission is proposed to explain both short- and longer-term therapeutic effects of DBS in GPi.

\section{Introduction}

Deep-brain stimulation (DBS) is a highly effective therapy for movement disorders (Kringelbach et al., 2007). When applied in the globus pallidus pars interna (GPi) DBS improves many of the pathological symptoms of Parkinson disease (PD) (Follett et al., 2010) and dystonia (Kiss et al., 2007), although on different time

Research to Z.H.T.K. We thank Drs. Clinton McCracken and Nicholas Strzalkowski for assistance during intraoperative data collection.

The authors declare no competing financial interests.

Correspondence should be addressed to Dr. Zelma Kiss, Room 1AC58, HRIC, 3280 Hospital Drive, NW Calgary, AB T2N4N1, Canada. E-mail: zkiss@ucalgary.ca.

https://doi.org/10.1523/JNEUROSCI.0785-18.2018

Copyright $\odot 2018$ the authors $\quad 0270-6474 / 18 / 3810734-13 \$ 15.00 / 0$ 


\begin{tabular}{|c|c|c|c|c|c|c|c|c|c|}
\hline \multirow[b]{3}{*}{ No. } & \multirow[b]{3}{*}{ Sex } & \multirow[b]{3}{*}{ Age, y } & \multirow[b]{3}{*}{ Diagnosis } & \multirow[b]{3}{*}{ UPDRS } & \multirow{3}{*}{$\begin{array}{l}\text { Disease } \\
\text { duration, y }\end{array}$} & \multicolumn{4}{|c|}{ After-effects of GPi neurons } \\
\hline & & & & & & \multicolumn{2}{|c|}{ Facilitation } & \multirow[b]{2}{*}{ Suppression } & \multirow[b]{2}{*}{ No change } \\
\hline & & & & & & Dis-c & c & & \\
\hline 3066 & $\mathrm{~F}$ & 52 & PD & 47 & 6 & 0 & 1 & 1 & 0 \\
\hline 3067 & $\mathrm{~F}$ & 67 & $P D$ & 69 & 13 & 2 & 1 & 1 & 1 \\
\hline 3068 & $M$ & 54 & MD & $51^{a}$ & 42 & 2 & 2 & 10 & 2 \\
\hline 3069 & $\mathrm{~F}$ & 68 & PD & 58 & 10 & 0 & 4 & 2 & 2 \\
\hline 3070 & $M$ & 71 & $P D$ & 54 & 7 & 0 & 1 & 5 & 3 \\
\hline 3071 & $M$ & 72 & $P D$ & 64 & 10 & 1 & 7 & 7 & 4 \\
\hline 3073 & $M$ & 69 & PD & 27 & 7 & 0 & 1 & 3 & 0 \\
\hline 3074 & $\mathrm{~F}$ & 75 & $C D$ & $48^{a}$ & 30 & 4 & 1 & 0 & 1 \\
\hline 3075 & $F$ & 27 & $\mathrm{GD}$ & 50 & 15 & 1 & 2 & 1 & 2 \\
\hline 3077 & $M$ & 60 & $C D$ & $19^{b}$ & 50 & 0 & 1 & 2 & 2 \\
\hline 3080 & $\mathrm{~F}$ & 72 & PD & 57 & 8 & 0 & 0 & 2 & 2 \\
\hline \multirow[t]{4}{*}{3082} & $M$ & 71 & PD & 69 & 12 & 1 & 0 & 0 & 0 \\
\hline & & & & & Total & 11 & 21 & 34 & 19 \\
\hline & & & & & PD & 4 & 15 & 21 & 12 \\
\hline & & & & & Dystonia & 7 & 6 & 13 & 7 \\
\hline
\end{tabular}

MD, myoclonic dystonia; CD, cervical dystonia; GD, generalized dystonia. Dis-c, discontinuous facilitation; c, continuous facilitation; UPDRS, The Unified Parkinson's Disease Rating Scale.

${ }^{a}$ The Burke-Fahn-Marsden Dystonia Rating Scale.

${ }^{b}$ TWSTRS, Toronto Western Spasmodic Rating Scale.

scales (Krauss et al., 2004). Although the immediate mechanisms of action of DBS applied to other targets have been characterized (Li et al., 2012), how DBS works in GPi remains controversial.

GPi is the output nucleus of the basal ganglia that relays neuronal firing to the ventral thalamic complex through GABAergic projections (Kuo and Carpenter, 1973). Abnormal firing and increased bursting activities in GPi are observed in both PD and dystonia patients compared with normal nonhuman primates (Starr et al., 2005; Nishibayashi et al., 2011), and these are associated with the off medication state in PD (Levy et al., 2001). In the treatment of movement disorders, GPi DBS is similar to pallidotomy (Merello et al., 1999) leading to the idea that inhibition of local GPi neurons is responsible for DBS benefit. Also in humans, low-frequency stimulation through a microelectrode in GPi induced short-lasting inhibition of local neural firing, whereas high-frequency stimulation (HFS) completely blocked firing (Dostrovsky et al., 2000). This inhibition is also observed as an after-effect following the cessation of GPi DBS and is thought to be mediated by GABA release from the predominant GABAergic afferents in the GPi (Lafreniere-Roula et al., 2010). With intense GABAergic inhibition, GPi-DBS dissociates inputs and outputs in the GPi and disrupts information flow through the GPi to thalamus and cortex (Chiken and Nambu, 2013). However, inhibition of GPi neurons cannot always explain the fact that GPi-DBS has therapeutic effects on both hypokinetic disorders, such as PD, and dystonia, which is a hyperkinetic disorder (McCairn et al., 2015). Studies in nonhuman primates report that GPi neural activity can be maintained or even increased and firing patterns are altered during DBS (Bar-Gad et al., 2004; McCairn and Turner, 2009) suggesting that DBS-induced excitatory responses in GPi may contribute to the therapeutic benefits through regularization of abnormally bursting neural firings. Although there is a study showing increased spiking in GPi neurons during DBS (Cleary et al., 2013), evidence for DBS-induced after facilitation and its contribution to regularizing the pathological bursting in human GPi are lacking.

Entopeduncular nucleus (EP) is the rodent equivalent of GPi and has been used as an animal model to explore the therapeutic mechanism of DBS (Shin et al., 2007; Shin and Carlen, 2008). GPi receives significant cholinergic inputs from the brainstem pedun- culopontine tegmental nucleus (PPN) in rodents (Woolf and Butcher, 1986) and primates (Lavoie and Parent, 1994). We recently showed that HFS applied inside the EP induces a prolonged after-depolarization, which was dependent on activation of cholinergic inputs and postsynaptic muscarinic receptors in rat brain slice (Luo and Kiss, 2016). No previous study has examined the DBS-induced delayed after-excitation in GPi, for any longer than the initial few seconds during and after HFS is applied. Therefore, there were three objectives of this study. One was to validate our findings in rodents by evaluating delayed increased spiking in patients with movement disorders undergoing microelectrode recordings in the GPi. We tested the hypothesis that high-frequency microstimulation applied in human GPi will produce after-effects with increased neuronal firing, similar to the membrane depolarization seen in our rodent model. The second objective was to analyze the changes in burst firing patterns after HFS. We hypothesize that the facilitatory after-effect may contribute to regularize the burst firing. The third objective was to explore the neural mechanism of the after-facilitation in rodent brain slice. We correlated human data to those obtained in the rodent slice model by seeking evidence for similar firing patterns. This could allow inferences to be made in humans based on the working mechanisms of HFS in EP brain slice.

\section{Materials and Methods}

\section{Human studies}

Subject demographics. Twelve patients (8 PD, 4 dystonia) who underwent stereotactic surgery for the implantation of DBS electrodes, were included in this study. Demographic and clinical details are summarized in Table 1. Collection of data from intraoperative recordings and microstimulation was approved by the University of Calgary Conjoint Health Research Ethics Board.

Intraoperative recordings. Single-unit recording in GPi was performed in awake patients undergoing mapping for placement of DBS electrodes. Only local anesthesia was used throughout the procedure. Our microelectrode recording methods have been previously described (Lee and Kiss, 2014). Before the implantation of the DBS electrode, two epoxycoated tungsten microelectrodes glued together (impedance: $0.1-1.0$ $\mathrm{M} \Omega$ at $1 \mathrm{kHz}$; distance between tips: $250-300 \mu \mathrm{m}$; FHC) were used to target the GPi. Neural signals were amplified $(5000 \times)$ and filtered (100 $\mathrm{Hz}$ to $10 \mathrm{kHz}$ bandpass) using NeuroSystem-2 (Atlantic Research Sys- 
tems), and recorded on VHS tapes with a digital recorder (CRC VR-AD 100, Instrutech). A stimulus generator plus constant-current isolator (A360 and A310, WPI) was used to generate monophasic pulses. All signals were replayed off-line and digitized at $10 \mathrm{kHz}$ for spikes (CED 1401, Cambridge Electronics Design). Locations of recording sites were reconstructed according to the predicted electrode trajectory based on a brain atlas (Shaltenbrand and Wahren, 1977). The atlas map was scaled to fit each patient's anterior and posterior commissure. Physiological landmarks were obtained from single-cell recordings and microstimulation data that allowed identification of regions with or without cellular activity (gray vs white matter), peripallidal border cells, the optic tract and the internal capsule (Lee and Kiss, 2014). Recordings started $15 \mathrm{~mm}$ above target so that the globus pallidus pars externa (GPe) was recorded first before entering the GPi. There was an area of white matter between the GPe and GPi, which was identified by a decrease in neural activity. The dorsal and ventral borders of GPi were identified by presence of slower, more regular firing "border" cells. Below the ventral border of GPi was a white matter region before the optic tract was reached. Optic tract was identified by visual percepts evoked by microstimulation (Fig. $1 A)$. The trajectory chosen for macro-electrode implantation was confirmed with postoperative imaging (Fig. 1B).

Experimental design. Once a single cell was isolated from the recording electrode, baseline spontaneous cell firing (spikes/s) was recorded for 1-2 min (prestimulation). A $10 \mathrm{~s}$ microstimulation train (frequency: $333 \mathrm{~Hz}$; pulse width: $0.2 \mathrm{~ms}$ ) was delivered either through the recording electrode $(10 \mu \mathrm{A})$ or the adjacent electrode $(100 \mu \mathrm{A})$. Spontaneous responses were continuously recorded for another 2-4 min (poststimulation) and used to evaluate the after-effect of DBS. Neurons that were lost right after microstimulation were excluded from analysis.

Digitized spike trains were visually inspected and imported into an off-line sorter (Plexon) for isolating populations of action potentials using principal components analysis and template-matching. Single units were accepted for analysis if they met two criteria (Liu et al., 2012): (1) Spike shape was consistent and could be separated from background noise and other neuronal spikes. (2) Interspike interval was not $<1.5 \mathrm{~ms}$ to help rule out the possibility of multiple neuron activity. Neuroexplorer (Plexon) was used for these analyses. Spike times were subsequently imported into MATLAB R2016a (MathWorks) to compute mean firing rates and characterize firing patterns. The after-effects induced by microstimulation were classified as facilitation, suppression, or no change, based on whether there was a 2 standard deviation (SD) change in mean spiking rate from baseline spontaneous firing. This classification was established by comparing mean firing rates in $0.5 \mathrm{~s}$ bin for $60 \mathrm{~s}$ at baseline with that in $0.5 \mathrm{~s}$ bins for $180 \mathrm{~s}$ after microstimulation (Cleary et al., 2013).

Because different types of responses were identified over the length of the recordings, we categorized responses based on periods of facilitation, suppression, or no change of spike rate compared with baseline. Two types of facilitation, continuous facilitation and discontinuous facilitation, were identified. Neurons were classified as having continuous facilitation if there was no reduction in firing between the peak facilitation and end of recording (up to $300 \mathrm{~s}$ ). Otherwise, neurons were classified as having discontinuous facilitation if a $>5 \mathrm{~s}$ period of decreased firing to baseline was observed between peak firing and end of recording. Suppression was defined as cells having at least $5-10 \mathrm{~s}$ of reduced firing after HFS.

Burst detection and firing pattern characterization. Bursts were defined as a cluster of closely spaced spikes (elevated discharge rate) from a single neuron (Lobb, 2014) using the Poisson surprise method having a minimum value of 3 (Legéndy and Salcman, 1985; Tang et al., 2007). In brief, the Poisson surprise value of a burst containing $N$ spikes with a period of $T$ from the first to the last spike is computed as follows: $S=-\log \left(\frac{\mathrm{N}}{\mathrm{T}}\right)$ First, average interspike intervals (ISIs) were determined for a given period of time (e.g., prestimulation and poststimulation periods). The ISI was compared spike-by-spike until at least three consecutive spikes whose ISIs are $\leq \frac{1}{2}$ the mean ISI value were found. Then, to maximize the Poisson surprise of a burst, an additional spike at the end of the burst was included to see whether it increased the value. The end of a burst was established when either a long ISI, greater than twice the average, was encountered or the Poisson surprise value did not increase when additional spikes (up to 10 spikes) were included in analysis.

Firing patterns, irregularity, and bursting activities were quantified using the following metrics (Tang et al., 2007; Alam et al., 2016): (1) dispersion index $\left(\mathrm{DI}=\frac{\text { standard deviation of } \mathrm{ISI}^{2}}{\text { mean ISI }}\right)$ for comparing variance in median ISI. Higher DI value would be indicative of higher random firing pattern with increased diversity of ISIs; (2) the coefficient of variation $(\mathrm{CV})$ was used to measure the regularity of a spiking train; (3) burst index $\left(\mathrm{BI}=\frac{\text { mean ISI }}{\text { mode ISI }}\right)$. Lower BI value is indicative of more regular spiking pattern; (4) asymmetry index $\left(\mathrm{AI}=\frac{\text { mode ISI }}{\text { mean ISI }}\right)$ as an index of the shape of ISI histogram. AI values closer to 1 are indicative of more regular spiking pattern; (5) total number of spikes within bursts per 1000 spikes; (6) percentage of spikes in bursts; (7) average burst duration; and (8) mean instantaneous frequency within bursts.

\section{Animal studies}

Brain slice preparation. Forty-five Sprague-Dawley rats (Charles River Laboratories) of either sex (postnatal days 11-20) were used for this study. Protocols of all the experiments were approved by the University of Calgary Animal Care Committee in accordance with the guidelines established by the Canadian Council on Animal Care. Rats were anesthetized with isoflurane and decapitated. The brains were quickly removed and immersed into ice-cold carbogen-bubbled $\left(95 \% \mathrm{O}_{2}-5 \% \mathrm{CO}_{2}\right)$ slicing solution (in mm: 207 sucrose, $2.5 \mathrm{KCl}, 26 \mathrm{NaHCO}_{3}, 1.0 \mathrm{CaCl}_{2}, 2.0 \mathrm{MgCl}_{2}$, $1.2 \mathrm{NaH}_{2} \mathrm{PO}_{4}$, and 10 D-glucose, $\mathrm{pH}$ 7.4). Coronal slices $(300 \mu \mathrm{m})$ were cut in carbogen-bubbled slicing solution with a vibratome (VT1000S, Leica) and transferred to a holding chamber that contained carbogenbubbled artificial cerebrospinal fluid (aCSF) solution (in mM: $126 \mathrm{NaCl}$, $2.5 \mathrm{KCl}, 26 \mathrm{NaHCO}_{3}, 2.5 \mathrm{CaCl}_{2}, 1.5 \mathrm{MgCl}_{2}, 1.25 \mathrm{NaH}_{2} \mathrm{PO}_{4}$, and 10 D-glucose, $\mathrm{pH} 7.4)$. EP slices were incubated for $60 \mathrm{~min}$ at $32-33^{\circ} \mathrm{C}$ and then kept at room temperature. Electrophysiological experiments were subsequently performed in a recording chamber perfused by aCSF at $32.5 \pm 0.5^{\circ} \mathrm{C}$.

Current-clamp recordings. The EP was visually recognized within the internal capsule and individual neurons identified using an upright microscope (Olympus BX51W) fitted with differential interference contrast optics. EP neurons were identified by electrophysiological properties described by Nakanishi et al. (1990). Whole-cell current-clamp recording was obtained from a slice placed in a chamber with carbogen-bubbled aCSF solution at a rate of $2-3 \mathrm{ml} / \mathrm{min}$. A borosilicate glass electrode (1.5 $\mathrm{mm}$ outer diameter; tip resistance 4-6 $\mathrm{M} \Omega$; King Precision Glass) filled with intracellular solution containing the following (in $\mathrm{mm}$ ): 108 K-gluconate, $8 \mathrm{Na}$-gluconate, $8 \mathrm{KCl}, 2 \mathrm{MgCl}_{2}, 1$ EGTA, 10 HEPES, 4 $\mathrm{K}-\mathrm{ATP}$, and $0.35 \mathrm{Na}-\mathrm{GTP}$ (pH 7.2 corrected with $\mathrm{KOH}$, osmolarity 286 $\mathrm{mOsm}$ ) was used to collect amplified current signals. All recordings were obtained using a Digidata 1440A acquisition system connected to an AxoPatch 200B amplifier (Molecular Devices). The recordings were lowpass filtered at $1 \mathrm{kHz}$, digitized at $10 \mathrm{kHz}$ online with Clampex 10.3, and analyzed off-line using Clampfit 10.3 (Molecular Devices). Once the recording was in whole-cell mode and stabilized following equilibration with the internal solution, passive membrane properties were measured. Constant $30-\mathrm{pA}$ current steps (10 steps starting at $-100 \mathrm{pA}$ ), $1 \mathrm{~s}$ in duration, were injected to obtain a current-voltage $(I-V)$ curve to measure input resistance and the action potential threshold. No series resistance compensation was performed. The data were accepted for off-line analysis only if changes in access resistance were $<20 \%$. The liquid junction potential was $14 \mathrm{mV}$, and reported voltage data were not corrected.

Electrical stimulation and "blanking" operation. A bipolar concentric electrode (NEX-100; Rhodes Medical Instruments) was used to deliver electrical stimulation with a constant-current stimulus isolator (A365; World Precision Instruments) connected to a stimulus generator (model 2100, A-M Systems). The stimulating electrode in EP was positioned such that single pulses could reliably evoke postsynaptic currents (PSCs) under voltage-clamp (clamped at $-60 \mathrm{mV}$ ). Stimulation trains (dura- 
A

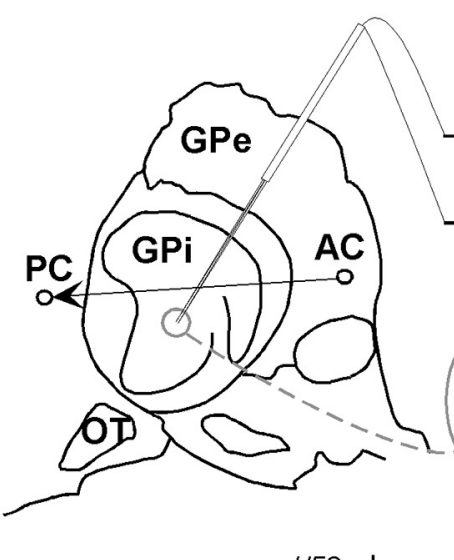

C
B

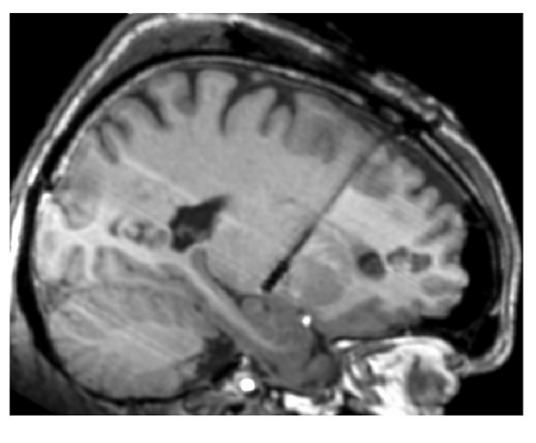

$\mathbf{B}$<smiles>[R]C1CC1</smiles><smiles>[SeH][Si]1([SeH])CCC[SiH2]1</smiles>
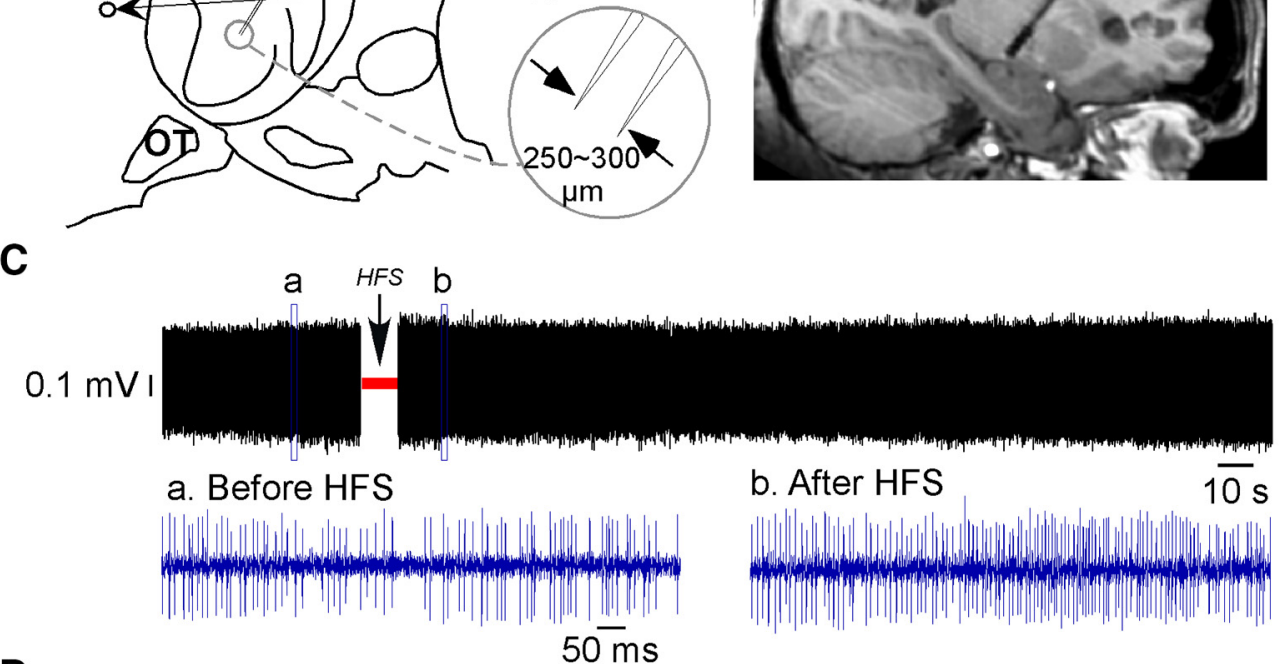

D Discontinuous facilitation
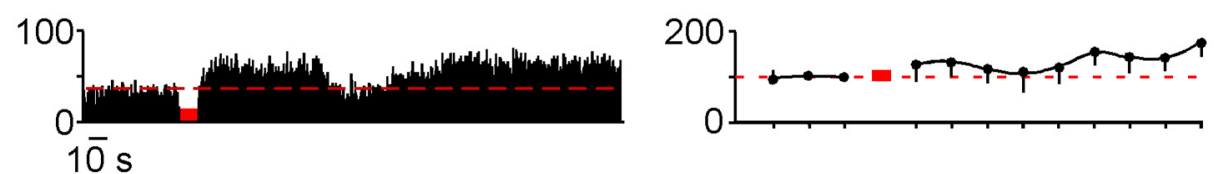

E

Continuous facilitation
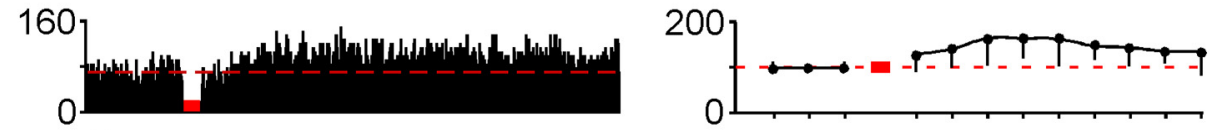

$\mathbf{F}$

$1 \overline{0} \mathrm{~s}$

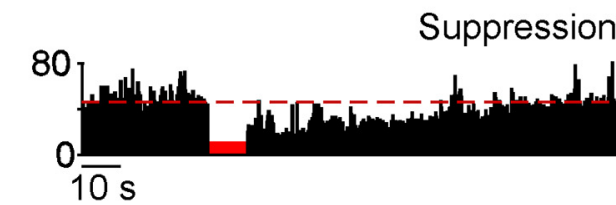

G
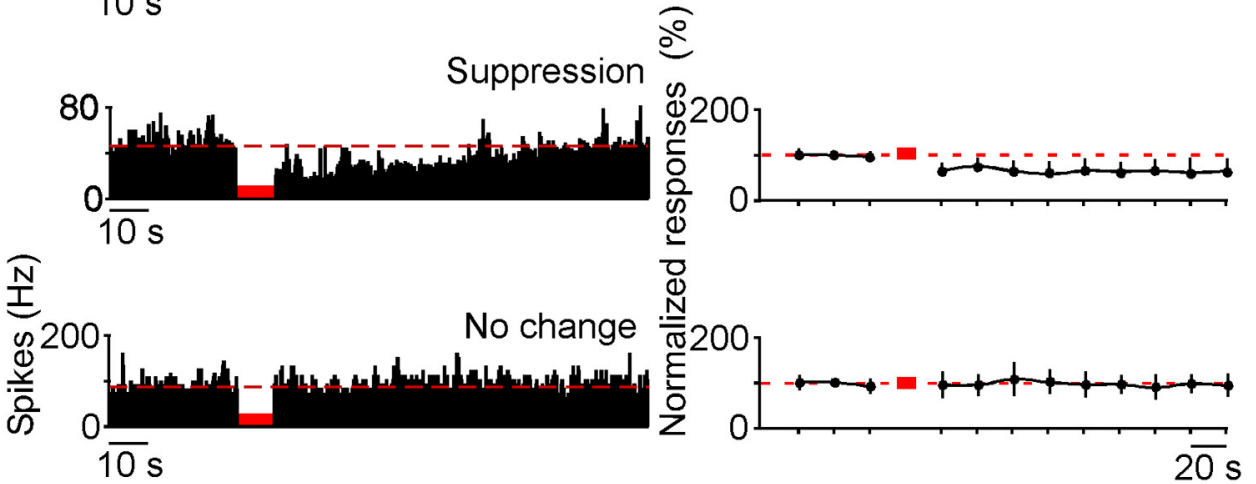

Figure 1. A, Schematic representation of a typical microelectrode track in the GPi extending ventrally to the optic tract (OT). ACindicates the anterior commissure, and the line with arrow indicates the AC-PC line extending toward the posterior commissure (PC). Inset, The distance between the two microelectrodes used for recording and stimulation. Single cells were recorded from the recording electrode and a $10 \mathrm{~s}$ HFS train was delivered either through the recording or adjacent electrode. $\boldsymbol{B}$, Postoperative magnetic resonance image showing the location of the implanted DBS electrode. C, The recording trace of the neuron in $\boldsymbol{D}$ (left) showing the spontaneous firing before and after HFS (bin width $0.5 \mathrm{~s}$ ). HFS in GPi resulted in discontinuous facilitation (D), continuous facilitation $(\boldsymbol{E})$, suppression $(\boldsymbol{F})$, or no change $(\boldsymbol{G})$ in spike rate in different cells. Dotted lines $(\boldsymbol{D}-\boldsymbol{G})$ indicate the average baseline firing rate. Right, Mean firing of all cell over time including SD lines.

tion $10 \mathrm{~s}$, frequency $125 \mathrm{~Hz}$ ) consisted of 60,150 , or $400 \mu$ s pulse-width square-wave monophasic pulses. To minimize the HFS applied, we usually started HFS using a current that produced $30 \%$ of a maximum PSC. For each pulse width, current was increased in $50 \mu \mathrm{A}$ increments until an obvious after stimulation effect was observed. HFS produces an artifact that can obscure membrane responses; therefore, blanking pulses $(0.1-$ $1.0 \mathrm{~ms}$ ) were used to eliminate the artifact during HFS (Anderson et al., 2004). Stimulation pulses generated by the stimulus generator also served as blanking pulses to initiate a blanking operation of the AxoPatch 200B amplifier. The membrane voltage was prevented from updating during each blanking pulse, thus the stimulation artifacts were largely reduced.

Experimental design. After measuring the membrane properties, the spontaneous response of a single neuron was recorded continuously at resting membrane potential. At least $60 \mathrm{~s}$ stable baseline was recorded before a HFS (frequency $125 \mathrm{~Hz}$, duration $10 \mathrm{~s}$, pulse width 60/150/400 
$\mu \mathrm{s})$ train was delivered. Responses were recorded up to 5 min after HFS. The after-effects induced by microstimulation were classified as excitation, inhibition and no change based on whether there was a 2 SD change in mean spiking rate from baseline spontaneous firing. Baseline average firing frequency and firing frequencies after HFS were compared per each $1 \mathrm{~s}$ bin. Two subtypes of increased firing based on periods of excitation only or excitation followed by reduced firing, which were similar to human recordings, were observed. Neurons were classified as excitation alone if there was no reduction in firing between the peak excitation and end of recording (up to $300 \mathrm{~s}$ ). Otherwise, neurons were classified as excitation with inhibition if a $>5 \mathrm{~s}$ period of inhibition was observed between peak firing and the end of recording.

Firing frequency (spikes/s) at resting membrane potential was measured using Clampfit and MATLAB. To evaluate the effect of different agonists and blockers on HFS, we chose $400 \mu$ s pulse width, because lower current amplitudes were required to see changes, relative to the amplitudes used with 60 and $150 \mu$ s pulse widths (Luo and Kiss, 2016). To record the same neuron with multiple applications of HFS, the response had to return to baseline before the subsequent stimulation was delivered. Experiments were ceased if the spontaneous response did not return to baseline in $5 \mathrm{~min}$. Peak firing frequencies (following HFS), frequencies during inhibition, and frequencies (measured for a $10 \mathrm{~s}$ period) at the end of the 5 min recording were compared among different protocols. To compare different neurons with different spontaneous firing rates using the same protocol, firing rate was normalized to baseline firing for each cell.

Chemicals. Chemicals were diluted in aCSF from aliquots [in distilled water or dimethyl sulfoxide (DMSO)] and applied by continuous bath perfusion to the slices. The final concentration of DMSO in aCSF was $<0.1 \%$, which had no effect on neuronal firing in control experiments. Ionotropic glutamatergic neurotransmission were blocked with a mixture consisting of either kynurenic acid $(\mathrm{KA} ; 2 \mathrm{~mm})$ or a mixture of 6,7-dinitroquinoxaline-2,3-dione (DNQX; $10 \mu \mathrm{M}$ ) and dl-2-amino-5phosphonopentanoic acid (D-AP5; $50 \mu \mathrm{M}$ ). Flufenamic acid (FA; $50 \mu \mathrm{M}$; nonspecific inhibitor of $\mathrm{Ca}^{2+}$-activated nonspecific cationic channels) was applied from stock solutions made in DMSO. DNQX, D-AP5, and FA were purchased from Tocris Bioscience. Atropine ( $4 \mu \mathrm{M}$; competitive cholinergic antagonist), KA, and all other chemicals were purchased from Sigma-Aldrich. After drug application, slices were washed with aCSF for up to $40 \mathrm{~min}$ until recovery to baseline occurred.

\section{Statistical analysis}

Off-line data analysis was performed in Clampfit v10.3 (Molecular Devices) and NeuroExplorer 5 (Plexon). Statistical analysis was performed using MATLAB and SPSS software v16.0 (IBM). Normality was checked using Kolmogorov-Smirnov test and Shapiro-Wilk test before further analysis. To compare differences in firing rates and patterns in PD and dystonia patients, Student's $t$ test was used if the data were normally distributed, and the Mann-Whitney $U$ test was used if data were not normally distributed. For comparisons of mean firing frequency induced by HFS at different time points or under aCSF versus bath application of drugs, repeated-measures ANOVA (RM-ANOVA), or Student's paired $t$ test was used; otherwise, nonparametric Friedman ANOVA was used to determine the significance, followed by post hoc Wilcoxon signed rank test for multiple comparisons of repeated measures. Chi-square test $\left(\chi^{2}\right.$ test) was used to compare different proportions of observations. All group data from both human and animal experiments are provided as mean $\pm \mathrm{SD}$. Results were considered significantly different when a $p$ value was $<0.05$.

\section{Results}

\section{After-effects induced by HFS in human GPi}

Experiments were performed at 134 recording sites in 51 different trajectories in 12 patients undergoing GPi exploration. Complete datasets available for analysis were obtained at 54 recording sites, yielding 85 distinct neurons. The firing rate for all recorded GPi neurons obtained from PD and dystonia patients had an average of $61.5 \pm 31.0 \mathrm{~Hz}$ at baseline and was not normally distributed with a skewness of $0.57(\mathrm{SE}=0.26)$ and a kurtosis of $-0.53(\mathrm{SE}=$ 0.52). GPi firing rate in $\mathrm{PD}$ patients $(68.3 \pm 32.0 \mathrm{~Hz}, n=52)$ was higher than that in dystonia patients $(50.9 \pm 26.3 \mathrm{~Hz}, n=33$; Mann-Whitney $U$ test, $Z=-2.538, p=0.011)$. A $10 \mathrm{~s}$ highfrequency microstimulation delivered through the recording ( $n=21$ neurons) or adjacent electrode ( $n=64$ neurons) resulted in similar poststimulation responses ( $\chi^{2}$ test, $p=0.229$ ) in spike rate: facilitation $(37.6 \%, 32 / 85)$, suppression $(40.0 \%, 34 / 85)$, or no change $(22.4 \%, 19 / 85)$ as shown in Figure $1(C-G)$.

Two subtypes of after-facilitation, discontinuous facilitation (Fig. 1D) or continuous facilitation (Fig. 1E), were observed based on the change in spike rate over time. In one neuron showing discontinuous facilitation, the average spike rate at baseline was $38.4 \pm 9.6 \mathrm{~Hz}$ and increased to $64.0 \pm 10.6 \mathrm{~Hz}$ for $65 \mathrm{~s} \mathrm{right}$ after HFS (Fig. 1C). The spike rate then decreased to below baseline level $(34.5 \pm 4.7 \mathrm{~Hz})$ before gradually increasing again over 4 min (Fig. 1D). In another neuron showing continuous facilitation (Fig. 1E), the spike rate was $68.7 \pm 10.4 \mathrm{~Hz}$ at baseline and increased to $98.5 \pm 12.5 \mathrm{~Hz}$ after stimulation. The afterfacilitation lasted for $>4 \mathrm{~min}$ before the spiking rate returned to baseline. In a neuron showing suppression (Fig. $1 F$ ), the average firing rate decreased from $45.9 \pm 8.8 \mathrm{~Hz}$ at baseline to $23.1 \pm 5.3$ $\mathrm{Hz}$ after stimulation. Overall, the firing rate of facilitated neurons increased from $54.0 \pm 29.3 \mathrm{~Hz}$ at baseline to $67.6 \pm 36.9 \mathrm{~Hz}$ after stimulation with a peak frequency (maximum firing frequency in $10 \mathrm{~s}$ bin after HFS) of $94.1 \pm 40.9 \mathrm{~Hz}(n=32$; Mann-Whitney $U$ test, $Z=-3.92, p<0.001)$. The average spike rate of all suppressed neurons decreased from $68.9 \pm 31.0 \mathrm{~Hz}$ at baseline to $42.6 \pm 25.9 \mathrm{~Hz}$ ( $n=34$; Mann-Whitney $U$ test, $Z=-3.46$, $p=$ 0.001 ) after stimulation with a valley frequency (minimum firing frequency in a $10 \mathrm{~s}$ bin after HFS) of $21.5 \pm 21.3 \mathrm{~Hz}$. In contrast, microstimulation had no effect on the firing rate of 19 neurons (Fig. $1 G$; baseline $61.0 \pm 32.1 \mathrm{~Hz}$ vs $52.8 \pm 27.7 \mathrm{~Hz}$ poststimulation; Mann-Whitney $U$ test, $Z=-0.77, p=0.452$ ).

Facilitation, suppression and no change subtypes were equally found in GPi neurons of both PD and dystonia patients. Figure 2 displays the temporal raster plots of all neurons in $\mathrm{PD}$ and dystonia patients. The poststimulation response types of facilitation $(36.5 \%, 19 / 52$ vs $39.4 \%, 13 / 33)$, suppression $(40.4 \%, 21 / 52$ vs $39.4 \%, 13 / 33)$ and no changes $(23.1 \%, 12 / 52$ vs $21.2 \%, 7 / 33)$ were comparable in both PD and dystonia patients ( $\chi^{2}$ test, $p=$ 0.957; Table 1; Fig. 2). The baseline frequencies of neurons showing facilitation, suppression and no change were $59.8 \pm 28.1$, $76.1 \pm 32.3,67.9 \pm 36.4 \mathrm{~Hz}$ in PD patients, and $45.5 \pm 29.9$, $57.2 \pm 25.8,49.1 \pm 20.2 \mathrm{~Hz}$ in dystonia patients. Although neurons with high spontaneous firing frequencies tended to have suppression after-effects, and neurons with lower spontaneous firing frequencies to have facilitatory after-effects, these differences among the groups were not statistically significant (MannWhitney $U$ test).

Previous studies have shown that, compared with normal nonhuman primates, GPi bursting activities are increased in both PD and dystonia patients (Starr et al., 2005) and GPi DBS is thought to exert its beneficial effect by modifying these abnormal bursts (Bergman et al., 1994; Hahn et al., 2008). Because others reported that firing patterns of GPi neurons become more regular during GPi-DBS (Cleary et al., 2013), we examined changes in regularity and bursts after stimulation, and related these to the observed changes in HFS-induced after-effects. In general, HFS decreased the dispersion index (Fig. 3A1,A2) and ISI CV (Fig. $3 B 1, B 2)$ in both PD and dystonia patients regardless of the aftereffects in GPi neurons. In only neurons with after-facilitation did the asymmetry index increase post-HFS (Fig. 3C1: PD, before 

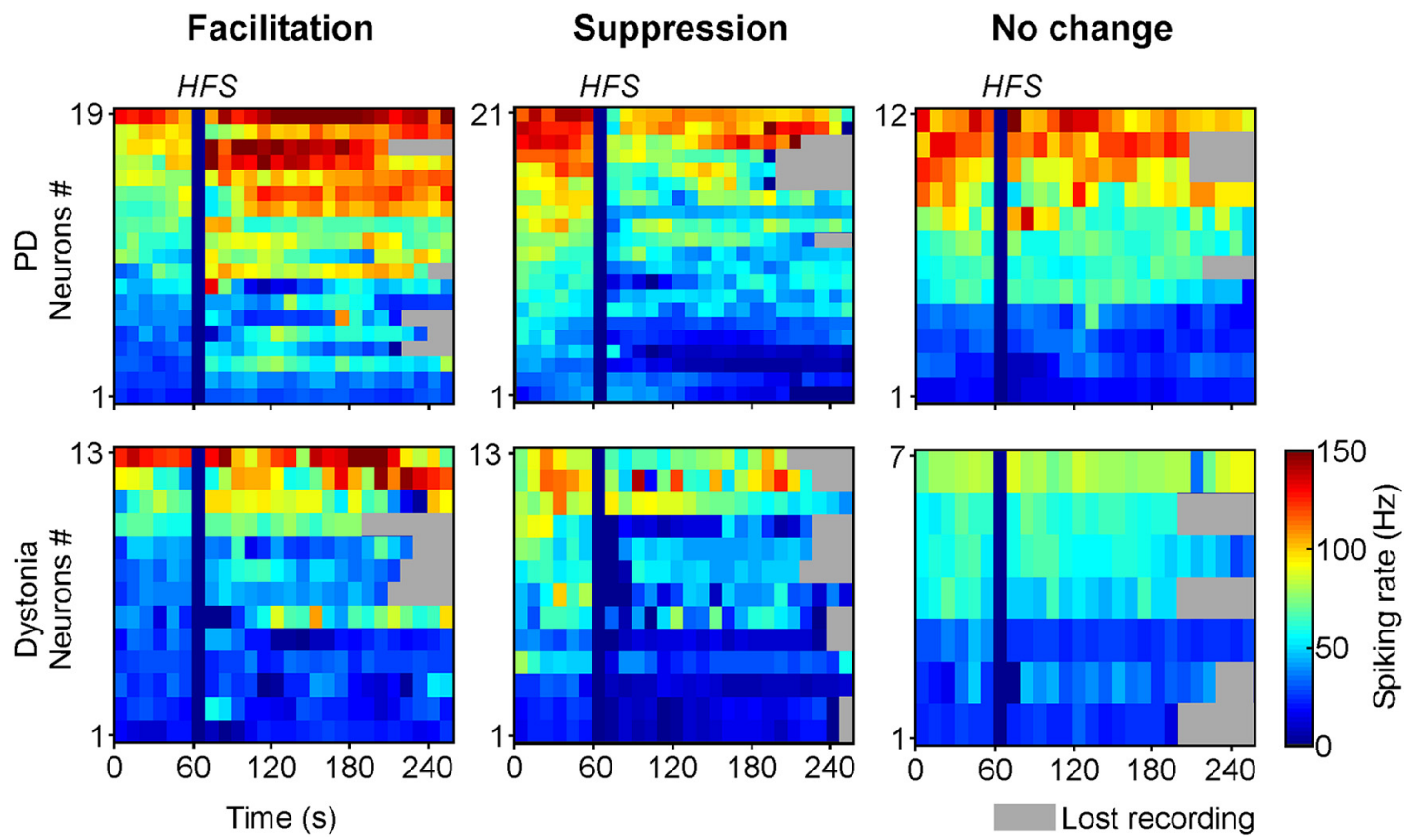

Figure 2. Temporal raster plots for each cell studied in Parkinson's disease and dystonia patients and how the different response types demonstrated. Each square in the surface plot represents the average spiking rate over $10 \mathrm{~s}$ period.

$0.30 \pm 0.16$, after $0.43 \pm 0.19$, paired $t$ test, $t=-4.02, p=0.001$; $C 2$ : dystonia, before $0.25 \pm 0.15$, after $0.43 \pm 0.23, t=-2.616$, $p=0.028$ ). Further analysis of burst index (Fig. 3D1) showed significant changes only in neurons with after-facilitation (PD, prestimulation $4.6 \pm 2.9$, poststimulation $3.4 \pm 1.7$, paired $t$ test, $t=3.427, p=0.003$; Fig. 3D2: dystonia, pre $5.7 \pm 3.2$, post $3.3 \pm$ $2.8, t=2.411, p=0.039)$. This suggests that GPi HFS may generally improve the regularity of local neuronal firing, but bursting activities may only reduce in neurons with a facilitation after-effect.

We next quantified the changes in bursting activities by comparing the burst number per 1000 spikes, percentage of spikes in bursts, average burst duration and instantaneous spiking frequency (ISF) within bursts, before and after HFS. In PD patients, HFS decreased both the burst number per 1000 spikes (Fig. 3E1; pre $11.6 \pm 3.4$, post $7.9 \pm 5.3$, paired $t$ test, $t=3.835, p=0.001$ ) and percentage of spikes in bursts (Fig. $3 F 1$; pre $63.5 \pm 17.0$, post $53.1 \pm 21.7$, paired $t$ test, $t=3.718, p=0.002$ ) only in GPi neurons with after-facilitation, and left the average burst duration unchanged (pre $1.4 \pm 1.5 \mathrm{~s}$, post $1.9 \pm 2.3 \mathrm{~s}$, Wilcoxon signed rank test, $Z=0.322, p=0.748)$. As a result of facilitation aftereffects, the ISF within bursts increased (pre $115.0 \pm 36.4$, post $148.1 \pm 46.4$, paired $t$ test, $t=4.358, p<0.001$ ). In neurons with suppression and no change, although HFS reduced the percentage of spikes in bursts (Fig. 3F1; suppression, pre $59.5 \pm 17.9$, post $34.1 \pm 15.2$, Wilcoxon signed ranks test, $Z=-3.18, p=$ 0.001 ; no change, pre $66.7 \pm 14.6$, post $41.7 \pm 13.9$, paired $t$ test, $t=8.211, p<0.001$ ), it increased the burst number in neurons with the suppression after-effect (Fig. $3 E 1$; pre $10.1 \pm 4.5$, post $21.2 \pm 12.8$, paired $t$ test, $t=4.212, p<0.001$ ) or no change (Fig. $3 E 1$; pre $12.6 \pm 4.8$, post $16.0 \pm 8.6$, paired $t$ test, $t=-2.768, p=$ 0.017 ), and reduced the average burst duration (no change, pre $1.0 \pm 0.5 \mathrm{~s}$, post $0.4 \pm 0.2 \mathrm{~s}$, paired $t$ test, $t=5.015, p<0.001$; suppression, pre $1.1 \pm 0.8 \mathrm{~s}$, post $0.4 \pm 0.4 \mathrm{~s}$, Wilcoxon signed rank test, $Z=-3.219, p=0.001)$.
In contrast to PD patients, HFS in dystonia patients did not reduce the bursting activities of neurons with facilitatory aftereffect (Fig. 3E2,F2), but only increased the ISF within burst (pre $71.7 \pm 41.6 \mathrm{~Hz}$, post $88.7 \pm 51.2 \mathrm{~s}$, paired $t$ test, $t=-3.514, p=$ 0.007 ), although it reduced the burst index in those neurons (Fig. 3D2). HFS appeared to affect the bursting patterns of the neurons with suppression after-effect or no change in a similar manner (i.e., increase in burst number and decrease in percentage of spikes in bursts and average burst duration) as in PD patients (Fig. 3E2,F2).

These results suggest that, generally, $10 \mathrm{~s}$-HFS was able to increase the regularity of spiking in GPi neurons in both PD and dystonia patients (Fig. $3 A, B$ ), and the effect was more obvious in neurons with after-facilitation than in neurons with aftersuppression and no change (Fig. $3 C$ ). There was a consistent reduction in both burst numbers and spikes in bursts (Fig. 3D-F) in neurons with after-facilitation in PD patients, but not in dystonia patients. In both PD and dystonia patient groups, HFS seemed to change the bursting activities in a similar manner in neurons with after-suppression and no change.

\section{After-effects induced by HFS in rodent EP}

To explore the cellular mechanisms of the HFS induced after excitation in GPi, we used current patch-clamp recording and studied the effects of HFS on EP neurons. Data were obtained in 78 neurons and 54 neurons had spontaneous firing at resting membrane potential. Only one neuron was tested for the effect of HFS per brain slice, and on average, 2-3 neurons were obtained from each animal. All the neurons were characterized as the major type I EP neurons according to the electrophysiological properties reported in previous studies (Nakanishi et al., 1990; Luo and Kiss, 2016). Animal data were normally distributed with a skewness of $0.524(\mathrm{SE}=0.448)$ and a kurtosis of $-0.282(\mathrm{SE}=0.872)$. 

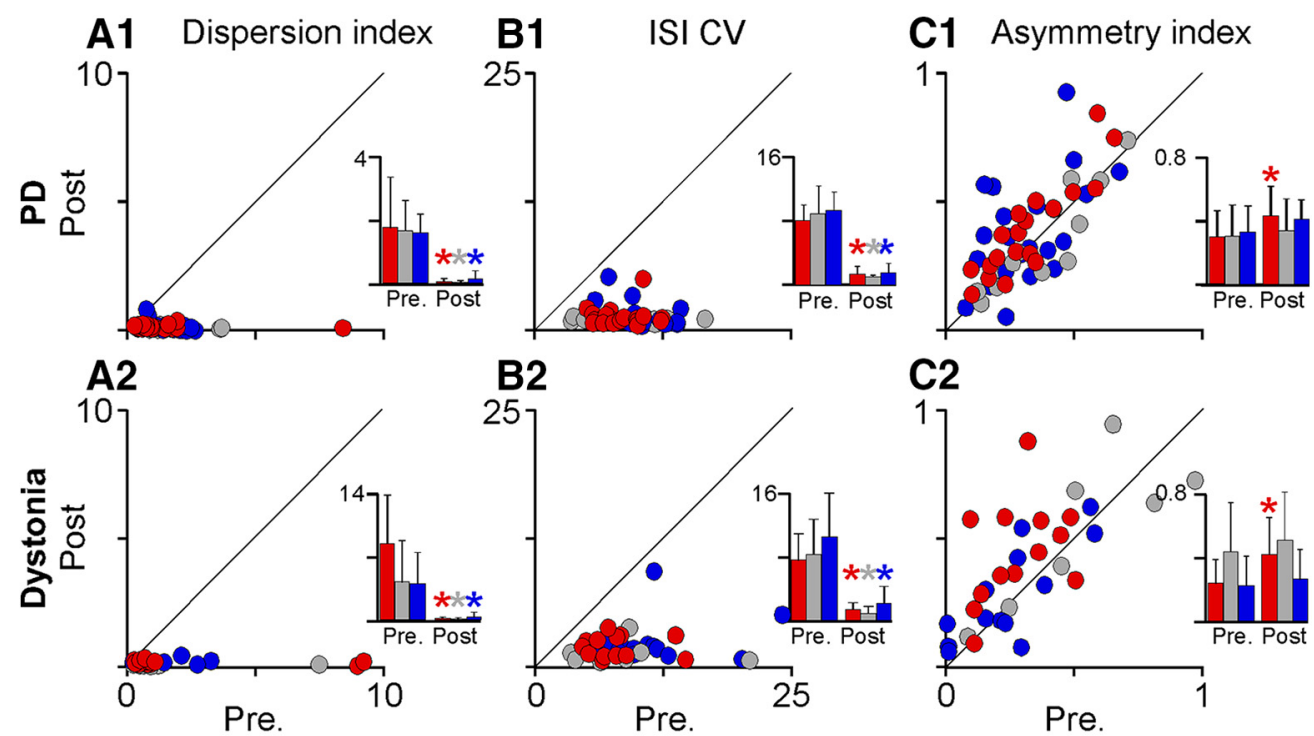

B2
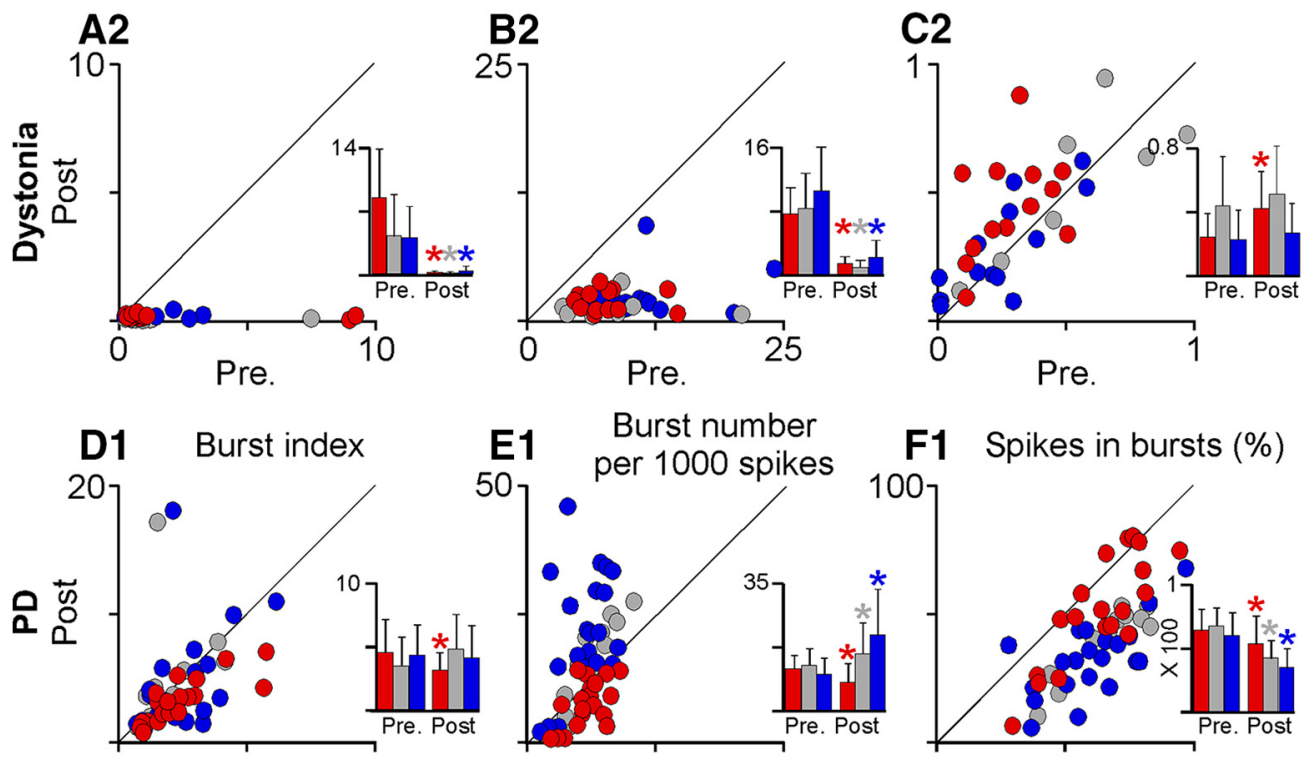

D2

E2
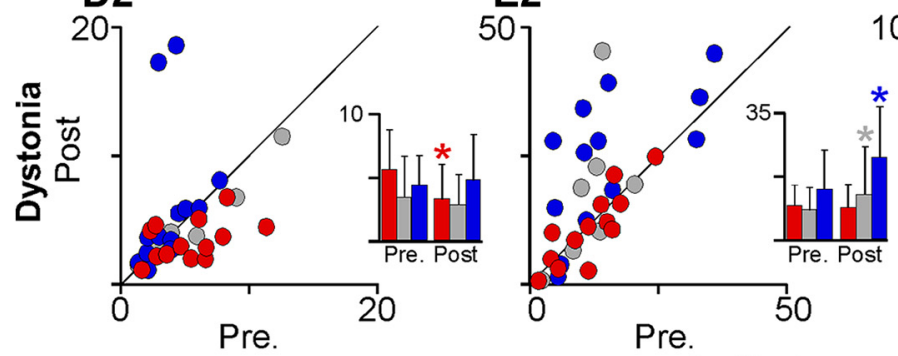

F2

- facilitation - suppression o no change

Figure 3. Changes in firing patterns of GPi neurons after HFS in PD and dystonia patient groups. For each cell, measured values prestimulation (Pre.) are plotted on the $x$-axis and poststimulation (Post) on the $y$-axis. Neurons showing different after-effects to HFS are represented by red (facilitation), gray (no change), and blue (suppression) circles, respectively. Group values are showed as a small bar graph beside each figure (* ${ }^{*}$ significant difference between values pre- and post-HFS using paired $t$ test or Wilcoxon signed rank test).

Seventy-four neurons showed after-excitation and four neurons showed only inhibition. Similar to the facilitations seen in human, a 10 s train of HFS inside EP induced two subtypes of after excitation in EP neurons: excitation alone or excitation with late inhibition. In a neuron showing excitation alone, the spontaneous firing frequency at control was $3.0 \pm 0.2 \mathrm{~Hz}$. It increased to $6.4 \pm 0.4 \mathrm{~Hz}$ right after the HFS and slowly decreased to $3.6 \pm 0.1 \mathrm{~Hz}$ over the 4 min recording period (Fig. $4 A$ ). In another neuron showing excitation with late inhibition, the spontaneous firing frequency increased from $1.3 \pm$ $0.4 \mathrm{~Hz}$ to $19.3 \pm 3.2 \mathrm{~Hz}$ right after the HFS (Fig. $4 B$, peak). This neuron showed a period of inhibition (79.2 s) following the peak frequency before the firing frequency increased again $(2.8 \pm 0.5 \mathrm{~Hz})$. Both subtypes of after-excitation could be induced with different pulse widths (60, 150 or $400 \mu$ s; Fig. 4C,D, average traces). Peak firing frequency of the excitation alone subtype displayed significant increases before returning to control levels at the end of recording (group data; Fig. $4 E ; t=2.84, p=0.015$, paired $t$ test). Firing frequency of excitation with late inhibition subtype exhibited a period of inhibition between the peak frequency and the frequency at the end of recording (group data; Fig. $4 F ; F=46.80, p<0.001$, RM-ANOVA).

The HFS current required to induce the excitation alone subtype was $191.7 \pm 87.7 \mu \mathrm{A}$ (using $400 \mu$ s pulse width, $n=28$ ), $290.0 \pm$ $74.2 \mu \mathrm{A}$ (using $150 \mu \mathrm{s}, n=6$ ), and $316.7 \pm 160.7 \mu \mathrm{A}$ (using $60 \mu \mathrm{s}$, $n=5$ ). Thresholds for inducing the excitation with inhibition subtype responses were $263.0 \pm 85.9 \mu \mathrm{A}$ (using $400 \mu \mathrm{s}, n=$ 23), $391.4 \pm 182.2 \mu \mathrm{A}$ (using $150 \mu \mathrm{s}, n=7$ ), and $811.6 \pm$ $432.0 \mu \mathrm{A}$ (using $60 \mu \mathrm{s}, n=5$ ). Overall, the threshold for inducing the excitation alone subtype was significantly lower than that required to induce excitation with late inhibition subtype $(222.4 \pm 106.0 \mu \mathrm{A}, n=35$ vs $364.2 \pm 263.0 \mu \mathrm{A}, n=$ $39, t$ test, $F=6.91, p=0.010)$, suggesting that the former is a subthreshold form of the latter. Examples at the opposite ends of the delivered charge density showed that HFS in EP induced initial inhibition and excitation at lower charge density (Fig. 4C, $60 \mu \mathrm{s}$ ), but excitation with late inhibition at higher charge density (Fig. 4D, $400 \mu \mathrm{s}$ ). 
A

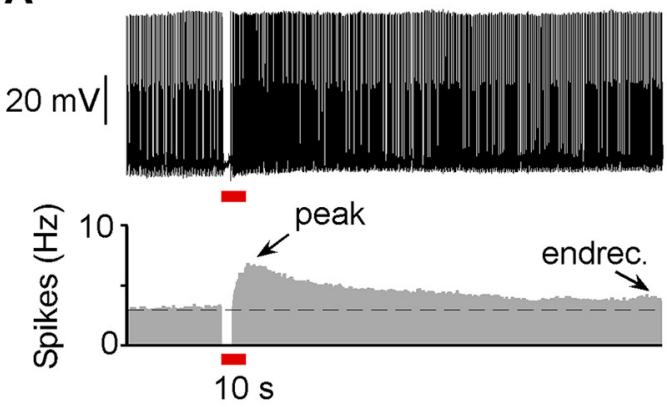

C

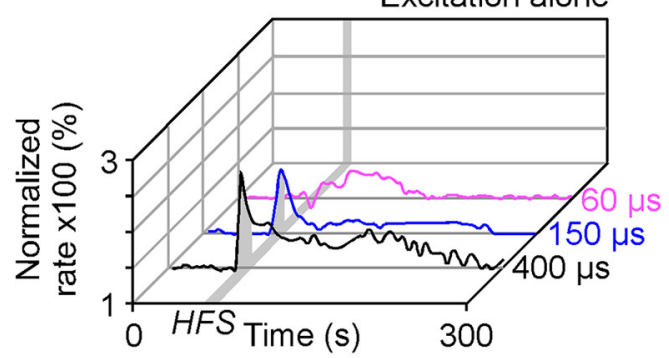

E

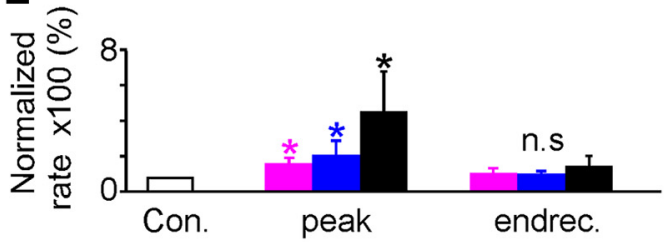

B
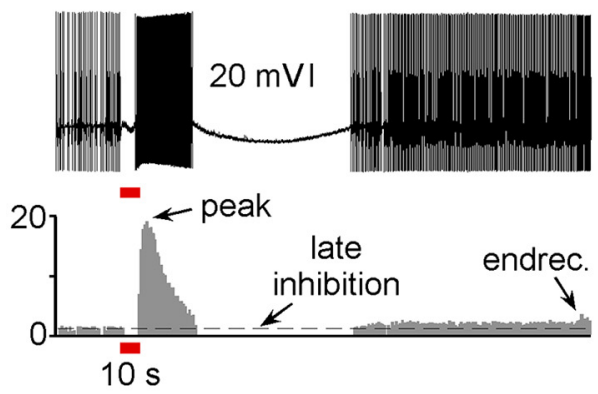

D

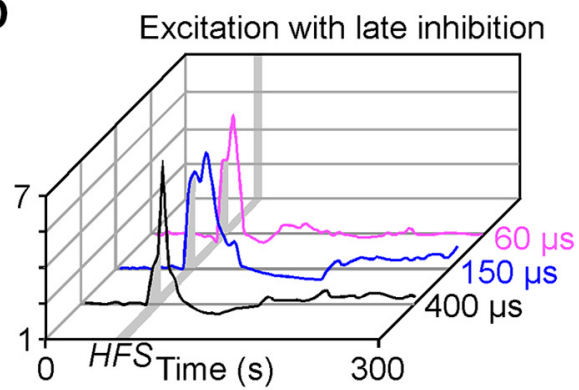

$\mathbf{F}$

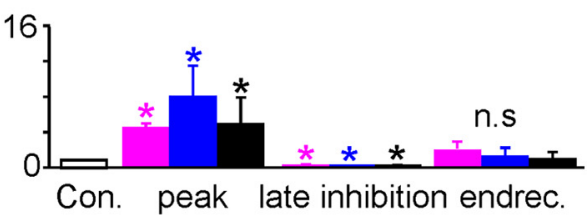

G

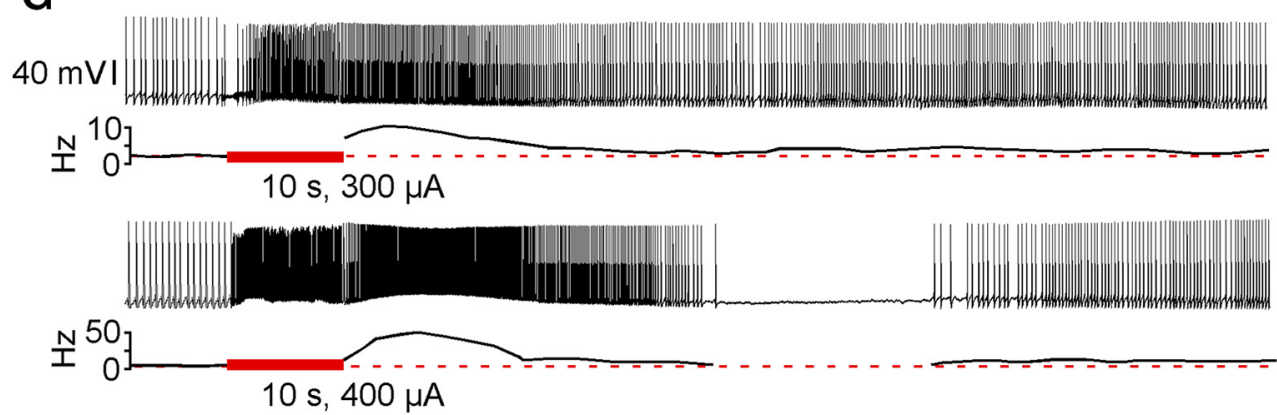

Figure 4. Similar to the spike patterns in humans, HFS in EP induced after-excitation in EP neurons of two subtypes, excitation alone ( $\boldsymbol{A})$ and excitation with late inhibition ( $\boldsymbol{B})$. Although both subtypes of after-excitation can be induced by HFS of different pulse width $(60,150$, and $400 \mu S ; C, D$, averaged traces) in different neurons, HFS with lower charge density tended to induce excitation alone $(\boldsymbol{C})$, whereas HFS applied at higher charge density induced excitation with late inhibition $(\boldsymbol{D})$. The excitation alone subtype showed significant increase in spiking rate $(\boldsymbol{E})$, whereas the excitation with inhibition subtype had an increase followed by a decrease in spiking rate $(\boldsymbol{F})$ right after HFS. The spiking rate returned to control levels at the end of recordings (labeled endrec, up to $300 \mathrm{~s} ; \boldsymbol{E}, \boldsymbol{F})$. ${ }^{*}$ Significant difference. Twenty neurons that had no spontaneous firing at resting membrane potential were not included in this figure. Among those neurons, 12 showed excitation alone and 8 showed excitation with late inhibition. $G$, HFS in EP induced after-excitation at low charge density ( $300 \mu \mathrm{A})$, but excitation with inhibition at high charge density (400 $\mu \mathrm{A})$ in the same EP neuron using pulse width of $400 \mu \mathrm{s}$.

To confirm that excitation alone and excitation with inhibition were associated with stimulation of low and high charge density in the same neurons, respectively, we tested the effects of HFS (pulse width $400 \mu \mathrm{s}, 125 \mathrm{~Hz}$, train duration $10 \mathrm{~s}$ ) using different intensities. First, excitation alone after-effects were induced at resting membrane potential with intensities ranging from 100 to $350 \mu \mathrm{A}$. After the spontaneous firing returned to baseline, another HFS was delivered with 50-100 $\mu \mathrm{A}$ higher intensity. Stimulations were limited to 3 in each neuron to minimize the residual effects of multiple stimulations. Figure $4 G$ is a representative neuron showing excitation alone after-effect at $300 \mu \mathrm{A}$ (top trace), but excitation with inhibition after-effect at $400 \mu \mathrm{A}$ (bottom trace). In all 15 tested neurons from 11 animals,
12 (10 spontaneous and 2 non-spontaneous) had excitation alone after-effects at $212.5 \pm 74.2 \mu \mathrm{A}$ that turned into excitation with inhibition after-effects at $310.4 \pm 79.4 \mu \mathrm{A}$. The excitation alone after-effect in 3 ( 2 spontaneous and 1 non-spontaneous) neurons did not change, but showed a longer duration of excitation when the intensity of HFS was increased from $166.7 \pm 76.4 \mu \mathrm{A}$ to $250.0 \pm$ $100.0 \mu \mathrm{A}$.

After-excitation in EP is dependent on glutamatergic, cholinergic synaptic transmission and $\mathrm{Ca}^{2+}$-activated non-specific cation (CAN) channels

The after-excitation in EP could be mediated by activation of direct glutamatergic inputs from subthalamic nucleus (Nambu, 

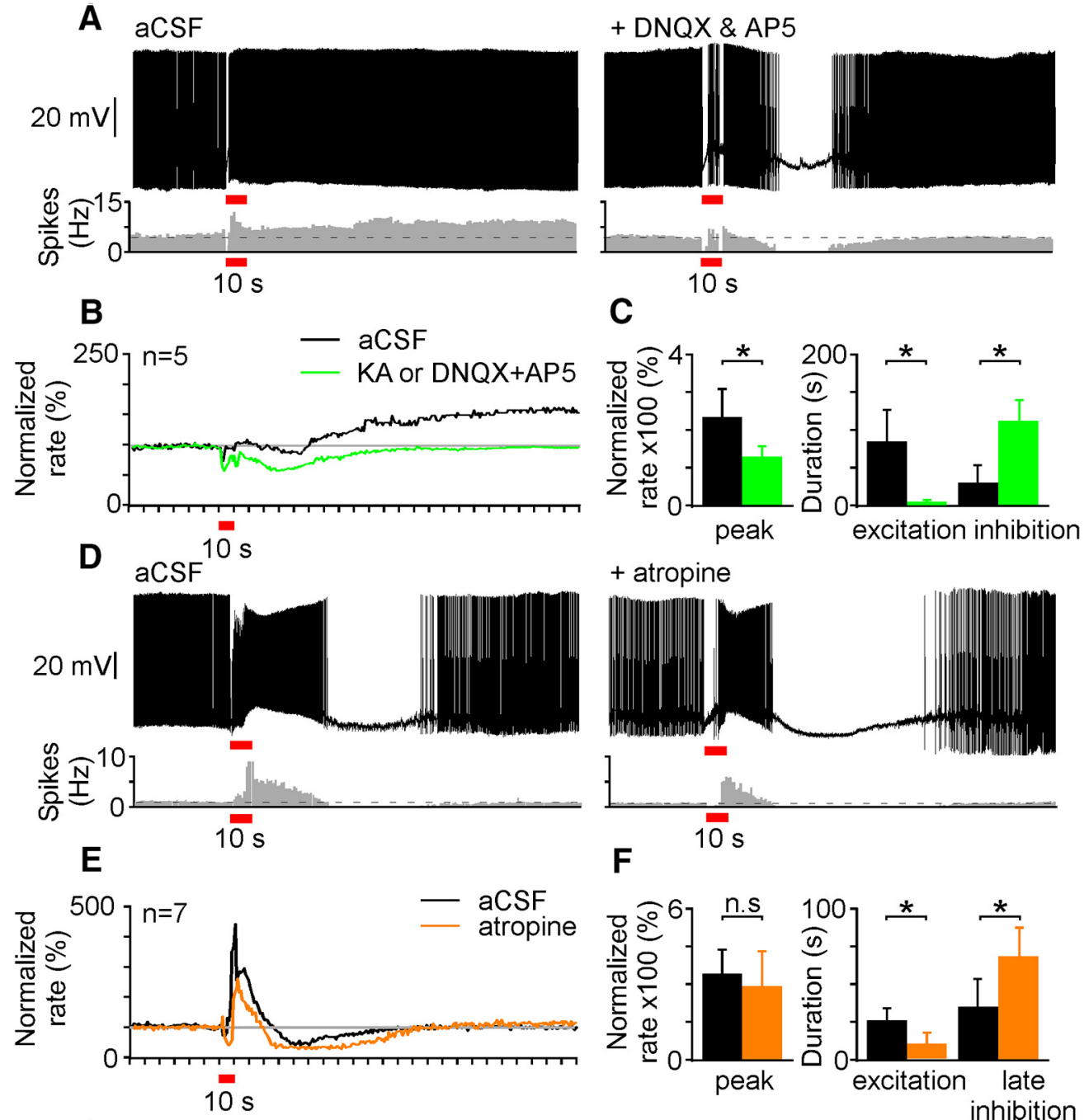

$\mathbf{F}$
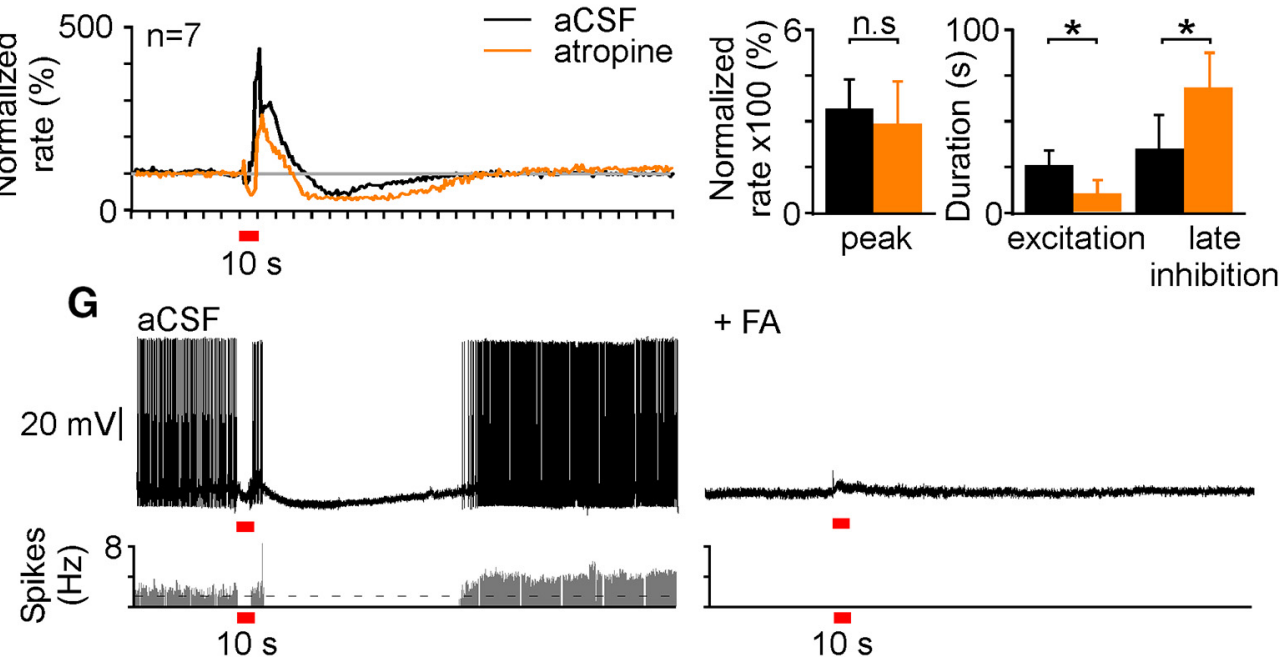

$+F A$

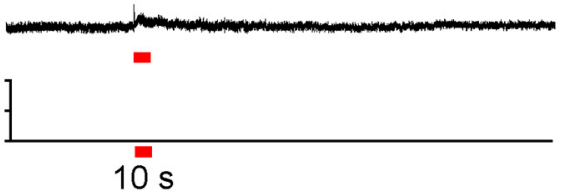

Figure 5. Synaptic blockade. A, Glutamatergic blockade with DNQX and AP5 eliminates HFS-induced after-excitation in rat EP when lower charge density is applied in individual cells (pulse width, $400 \mu \mathrm{s}$; amplitude, $100 \mu \mathrm{A}$ ). B, Mean normalized firing rates in all five cells studied using average HFS of $300 \pm 154 \mu$ A. Blockade of AMPA and NMDA receptors significantly decreased the peak spiking rate $(\boldsymbol{C}$, left), duration of excitation, and increased the duration of inhibition ( $\boldsymbol{C}$, right). $\boldsymbol{D}$, Cholinergic synaptic transmission is involved in HFS-induced after-excitation in this exemplar (pulse width, $400 \mu \mathrm{s}$; intensity, $300 \mu \mathrm{A}$ ). E, Normalized averages of all seven cells studied using high charge densities (mean $486 \pm 180 \mu \mathrm{A}$ ). Blockade of cholinergic receptors with atropine significantly reduced the duration of after-excitation leaving the HFS induced peak frequency unchanged $(\boldsymbol{F})$. CAN channels blocker FA completely blocked spontaneous activities and after effects in all five tested neurons (G).

2007) and/or cholinergic projections from brainstem (Clarke et al., 1997). Our previous study (Luo and Kiss, 2016) demonstrated that HFS induces after-depolarizations in EP, which require high charge density and are mediated by muscarinic acetylcholine receptor (mAChRs) and CAN channels. Thus, we postulated that the after-excitation may be mediated by glutamatergic neuronal transmission at lower charge density and by glutamatergic, cholinergic modulation and CAN channels at higher charge density.

To test this hypothesis, three groups of experiments were performed. In one group of experiments, cells exhibiting excitation alone at low charge density (Fig. 5A, left) underwent bath application of glutamatergic blockers (KA or DNQX plus AP5). A representative neuron showed that blockade of ionic glutamatergic synaptic transmission not only abolished the after-excitation, but also unmasked a significant period of the inhibition induced by HFS (Fig. $5 A$, right, $B$, average traces). Mean peak frequency and excitation duration dropped from $235.8 \pm 73.9 \%$ to $123.3 \pm$ $30.3 \%(t=2.93, p=0.039$, paired $t$ test; $n=5)$, and $84.3 \pm 41.5 \mathrm{~s}$ to $1.5 \pm 2.3 \mathrm{~s}(t=2.63, p=0.046)$, respectively, whereas the inhibition period increased from $29.6 \pm 13.8 \mathrm{~s}$ to $110.0 \pm 26.0 \mathrm{~s}$ 
$(t=-3.18, p=0.034$; Fig. $5 C)$. In a second group of experiments, cells displaying the excitation with late inhibition response, when HFS was applied at higher charge density, were subjected to atropine to block the cholinergic receptors on EP neurons. Figure $5 D$ shows a representative neuron where atropine decreased the duration of HFS induced after excitation. As a result, the duration of inhibition following the initial after excitation period increased (Fig. $5 E$, average traces). On average, the duration of after excitation decreased from $21.0 \pm 7.5 \mathrm{~s}$ to $10.6 \pm$ $8.7 \mathrm{~s}$ (paired $t$ test, $t=5.16, p=0.002 ; n=8$ ), whereas the late inhibition duration increased from $35.0 \pm 17.6 \mathrm{~s}$ to $67.6 \pm 18.5 \mathrm{~s}$ $(t=-2.99, p=0.024 ; n=8$; Fig. $5 F)$. Unlike the excitation alone subtype, the excitation with inhibition subtype did not show a significant change in peak frequency after atropine (327.9 \pm $95.7 \%$ vs $296.0 \pm 157.5 \% ; t=0.29, p=0.782$; Fig. $5 F)$. In a third group of experiments, FA was used to block CAN channels when the excitation with inhibition responses were induced with HFS. A representative neuron showed excitation with inhibition response after $10 \mathrm{~s}$ HFS ( $400 \mu \mathrm{s}, 200 \mu \mathrm{A}, 125 \mathrm{~Hz})$ with an average duration of after-excitation $137 \pm 33.5 \mathrm{~s}$, late inhibition duration $32.0 \pm 28.1 \mathrm{~s}$ and normalized peak frequency $360.9 \pm 227.2 \%$ $(n=5)$. In all tested neurons, both the spontaneous spiking and after-excitations were abolished when FA was applied in the bath (Fig. $5 G$ ).

In summary, HFS induced after-facilitation in a substantial proportion of human GPi neurons $(37.6 \%, 32 / 85)$. This HFSinduced after-effects on spiking rate may contribute to alleviating the pathological bursting activities. $10 \mathrm{~s}$ stimulation was able to increase the regularity and reduce the bursting activities in GPi neurons with after facilitation. Interestingly, this immediate after-effect on bursting activities were observed in PD, but not dystonia patients. Further study in the GPi equivalent structure in rats showed similar after-effects in EP brain slice, excitation alone or excitation with late inhibition. The excitation alone subtype, induced by lower charge density, was dependent on glutamatergic transmission, whereas the excitation with late inhibition subtype, induced by higher charge density HFS, involved glutamatergic, cholinergic modulation and CAN channels.

\section{Discussion}

DBS in GPi is thought to relieve symptoms of PD and dystonia through its effect on local and remote neural elements (Kringelbach et al., 2007). In vitro experiments generated a hypothesis that HFS in EP may induce excitation as well as inhibition (Luo and Kiss, 2016). Here we tested this in human GPi and found that high-frequency microstimulation indeed induced a prolonged after-facilitation in more than one-third of neurons. This aftereffect was of two types, continuous or discontinuous facilitation, likely depending on the HFS charge density. $10 \mathrm{~s}$ HFS increased the firing regularity of all GPi neurons, more obviously in neurons with after-facilitation. HFS reduced bursting in all neurons; however, it decreased significantly in neurons with afterfacilitation in PD patients, but not dystonia patients. Further pharmacological experiments in rodent EP identified that the HFS induced excitatory after-effects were mainly mediated by glutamatergic neurotransmission at low charge density, but involved cholinergic modulation at high charge density.

\section{Cellular mechanism of HFS in GPi/EP}

In EP neurons HFS induced either after-excitation alone or afterexcitation with late inhibition, both of which could be induced by different pulse widths. High pulse width (400 or $150 \mu$ s) HFS had lower threshold to induce after-excitation than low pulse width
(60 $\mu \mathrm{s})$, suggesting that charge density is key. HFS inducing excitation alone had a lower threshold than excitation with late inhibition, also suggesting that the former may be a subthreshold form of the latter. This is analogous to what we observed in human GPi. Although the same stimulation intensity was used, the actual charge density delivered to each recorded cell varied depending on the local neural elements and orientations of its axonal afferents (Ranck, 1975; McIntyre et al., 2004). The charge density delivered to the recording site may be lower in some neurons, but higher in others. Therefore HFS with lower delivered charge density may lead to continuous facilitation, whereas HFS with higher delivered charge density may lead to discontinuous facilitation.

The GPi/EP receives glutamatergic inputs from STN, GABAergic inputs from GPe and striatum, and cholinergic inputs from PPN (Prescott et al., 2006; Nambu, 2007). Because at lower charge density, the excitation alone after-effect in EP neurons was completely blocked by AMPA and NMDA receptor antagonists, these effects occurred mainly through activation of fast glutamatergic and GABAergic transmission. Increased spiking during HFS at low charge density and/or after HFS because of glutamatergic transmission can lead to increase in intracellular $\mathrm{Ca}^{2+}$ through NMDA receptor and high voltage-gated $\mathrm{Ca}^{2+}$ channels (Ludwig et al., 1997; Cole et al., 2005), which then activate CAN channels (Partridge and Swandulla, 1988). The CAN channels that are permeable to $\mathrm{Na}^{+}$and $\mathrm{Ca}^{2+}$ lead to long-lasting depolarization of membrane potential (Rahman and Berger, 2011), which may contribute to the after-excitation. At higher charge density, the after-excitation with inhibition subtype had a shorter excitation and longer inhibition duration leaving peak frequency right after HFS unchanged when $\mathrm{mAChR}$ were blocked by atropine. This indicates that higher charge density stimulation resulted in more neurotransmitter release with fast glutamatergic transmission contributing to the initial spiking increase right after HFS. Meanwhile, activated cholinergic fibers may release enough ACh (Cubeddu and Hoffmann, 1983) to affect postsynaptic neural activities through $\mathrm{mAChR}$ on a longer time scale. This is supported by our previous findings that blockade of AMPA, NMDA, $\mathrm{GABA}_{\mathrm{A}}, \mathrm{GABA}_{\mathrm{B}}$, and $\mathrm{nAChR}$ receptors did not prevent HFS from inducing after-excitation (Luo and Kiss, 2016). The excitatory effects of ACh may be linked to blockade of G-protein-coupled inwardly rectifying $\mathrm{K}^{+}$channel (Krnjević, 2004) and/or activation of CAN channels through the phospholipase C pathway (Rahman and Berger, 2011).

The inhibition in both subtypes of after-excitation could come from different sources depending on the time course. HFS may activate striatal terminals to induce $\mathrm{GABA}_{\mathrm{A}}$ receptor activation (Kita, 2001) and also affect GPe terminals to induce prolonged $\mathrm{GABA}_{\mathrm{B}}$ responses in GPi neurons (Kita et al., 2006). The prolonged early inhibition may result from the temporal summation of $\mathrm{GABA}_{\mathrm{A}}$-mediated IPSPs induced by each stimulus in the HFS train (Dostrovsky et al., 2000). The late inhibition seen with the excitation with late inhibition subtype response could be because of activation of postsynaptic $\mathrm{GABA}_{\mathrm{B}}$ receptors (Kaneda and Kita, 2005). Additionally, influx of intracellular $\mathrm{Ca}^{2+}$ may lead to an increase of $\mathrm{Ca}^{2+}$-activated $\mathrm{K}^{+}$conductance (Vergara et al., 1998). Thus, both GABAergic transmission and $\mathrm{Ca}^{2+}$ activated $\mathrm{K}^{+}$conductance may contribute to the inhibition of spontaneous spikes in EP neurons.

Electrophysiological studies in both humans and nonhuman primates show that DBS effects are dependent on distance from the stimulation site, electrode orientation, and the neural elements activated (Kringelbach et al., 2007). When the charge den- 


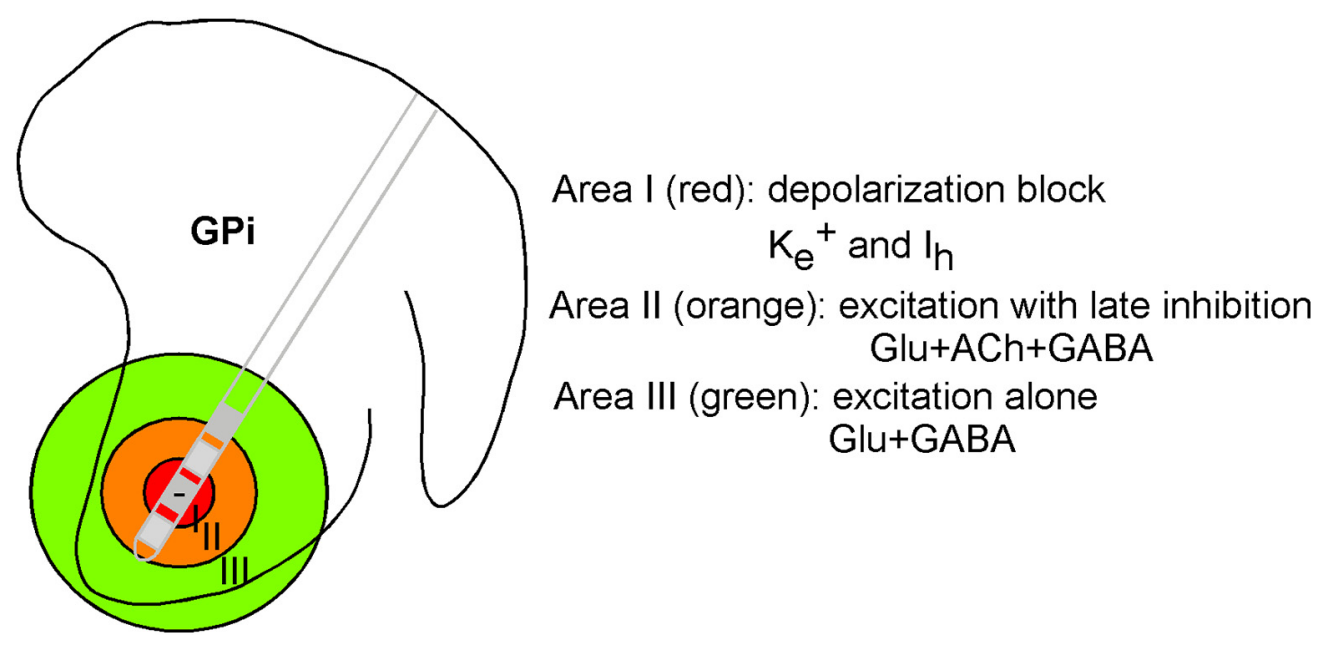

Figure 6. Cellular effects at the site of stimulation in sagittal view through the human GPi (as in Fig. 1A). With monopolar DBS an approximately spherical volume of brain tissue around the cathode is activated. The mechanisms involved in areas I, II, and III vary and depend on the current density/distance away from the cathode.

sity of HFS is increased, by an increase in pulse width or current amplitude, the region of affected tissue is increased accordingly (Ranck, 1975). Here we propose a working model to explain the cellular effects of DBS in GPi (Fig. 6). DBS stimulates a spherical volume of brain tissue around the electrode. According to the distances from the DBS cathode in GPi, three roughly spherical areas, which receive different charge density, display different predominant cellular effects (Fig. 6). Area I (in red) is closest to the electrode and likely involves depolarization block: because the charge density delivered in this area is highest, DBS may induce massive spikes of neurons leading to the elevation of extracellular $\mathrm{K}^{+}$level (Shin et al., 2007; Shin and Carlen, 2008). Area II (in orange) is an area receiving moderate charge density where neurotransmitter release through both ionotropic and metabotropic receptors occurs. In EP, this area may contain the cells responding to HFS with after-excitation and late inhibition and is modulated by glutamate, GABA, and acetylcholine. Area III (in green) is the outermost volume that is locally affected by HFS. The charge density delivered in this area may only affect cellular activities through fast glutamatergic and GABAergic transmission, which may lead to either inhibition or the excitation alone subtype response to HFS.

\section{Implications to the therapeutic mechanisms of DBS in GPi}

DBS induces both excitatory and inhibitory effects on local elements surrounding the electrode and reduction of pathological rhythmicity such as burst activities may contribute to the therapeutic effect (Rubin and Terman, 2004; Hahn et al., 2008). We found that $10 \mathrm{~s}$ HFS induced excitatory after-effects, led to more regular firing patterns through reduction of bursts in PD patients, but not dystonia patients. One previous study reported excitation during DBS in human GPi (Cleary et al., 2013), but did not explain the source of this excitation and its contribution to spiking pattern change. The cholinergic mechanism proposed here may provide an additional explanation for the short- and longer-term mechanism of action of DBS in GPi.

$\mathrm{PD}$ is characterized by degeneration of dopaminergic nigrostrial neurons, which results in abnormal increase in the GPi firing rate (DeLong, 1990), whereas dystonia shows evidence of loss of inhibition, sensory dysfunction, and significant alterations of synaptic plasticity (Quartarone and Hallett, 2013). In line with previous reports (Starr et al., 2005), GPi firing rate in our popu- lation was higher in PD patients than in dystonia patients. Despite the difference in baseline firing rate, HFS induced a comparable percentage of after-facilitation in both PD and dystonia patients. This after-facilitation likely has both glutamatergic and cholinergic origin because activation of STN efferent fibers causes excitation in GPi (Hashimoto et al., 2003) and GPi-HFS is also known to modulate neurons in cholinergic pedunculopontine tegmental nucleus (Zhang et al., 2012). Both glutamatergic and cholinergic modulation may contribute to the afterfacilitation that led to disrupting the abnormal activity and transmission in the basal ganglia-thalamo-cortical circuitry through GPi. In PD patients, this effect could be fast acting because $10 \mathrm{~s}$ HFS was able to increase the firing regularity and rapidly reduce the bursting patterns of GPi neurons (Fig. 3). However, in dystonia patients, although $10 \mathrm{~s}$ HFS increased the regularity of the firing in general (Fig. $3 A, B$ ), it had no significant effect on bursting. This may contribute to the different time frame needed for symptom improvement in PD and dystonia patients (Krauss et al., 2004). Cholinergics could be involved in the long-term therapeutic benefit of DBS because cholinergic signaling plays an important role in shaping nervous system function, plasticity, and behavior (Picciotto et al., 2012; Jiang et al., 2016). For example, PPN activation can induce auditory plasticity in both medial geniculate body (Luo et al., 2011) and cortex (Luo and Yan, 2013) through cholinergic innervation to thalamus and midbrain. Gradual improvement in dystonia patients by GPi DBS (Krauss et al., 2004) may be related to cholinergic modulation of GPi and result in more gradual effects on sensorimotor cortical reorganization.

Interestingly, anticholinergic drugs acting on $\mathrm{mAChR}$ have been used in PD and dystonia patients because of the dopamine acetylcholine imbalance in striatum (Pisani et al., 2007). At first glance this may appear contradictory to our current findings, which propose a cholinergic mechanism for DBS benefits, however it is not. First, the anticholinergics commonly used to treat PD and dystonia clinically are nonselective and therefore limited by central and peripheral adverse effects (Langmead et al., 2008). For example, anticholinergics have been used for primary dystonia, but are less effective and poorly tolerated in adults (Burke and Fahn, 1983; Burke et al., 1986). Second, there are five subtypes of mAChRs with different roles widely distributed in the CNS. Postsynaptic mAChR (M1 group) is mainly excitatory, 
whereas presynaptic and postsynaptic M2 group mAChRs are largely inhibitory (Wess et al., 2003). Our animal data implicated the postsynaptic M1 group $\mathrm{mAChR}$ in the excitatory after-effects in EP neurons (Luo and Kiss, 2016).

\section{Potential limitations}

The cholinergic system undergoes dramatic changes in movement disorders (Conti et al., 2018). The current study was performed in healthy rat brain and not a model of disease; therefore, we must be cautious in our extrapolation to the human pathological condition. Although it would be interesting to see how HFS-induced after-excitatory effects are altered in a pathological rat model, it is not feasible to obtain recordings from EP slice later in life, because of the myelination of fibers in the internal capsule of adult rats.

In conclusion, by recording from human GPi and dissecting the cellular mechanisms in rats, our work indicates that GPi DBS may regularize the neuronal firing and disrupt the burst activities through the brain cholinergic system, which contributes to both the immediate and gradual therapeutic effects in PD and dystonia.

\section{References}

Alam M, Sanghera MK, Schwabe K, Lütjens G, Jin X, Song J, von Wrangel C, Stewart RM, Jankovic J, Grossman RG, Darbin O, Krauss JK (2016) Globus pallidus internus neuronal activity: a comparative study of linear and non-linear features in patients with dystonia or Parkinson's disease. J Neural Transm 123:231-240. CrossRef Medline

Anderson T, Hu B, Pittman Q, Kiss ZH (2004) Mechanisms of deep brain stimulation: an intracellular study in rat thalamus. J Physiol 559:301-313. CrossRef Medline

Bar-Gad I, Elias S, Vaadia E, Bergman H (2004) Complex locking rather than complete cessation of neuronal activity in the globus pallidus of a 1-methyl-4-phenyl-1,2,3,6-tetrahydropyridine-treated primate in response to pallidal microstimulation. J Neurosci 24:7410-7419. CrossRef Medline

Bergman H, Wichmann T, Karmon B, DeLong MR (1994) The primate subthalamic nucleus: II. Neuronal activity in the MPTP model of parkinsonism. J Neurophysiol 72:507-520. CrossRef Medline

Burke RE, Fahn S (1983) Double-blind evaluation of trihexyphenidyl in dystonia. Adv Neurol 37:189-192. Medline

Burke RE, Fahn S, Marsden CD (1986) Torsion dystonia: a double-blind, prospective trial of high-dosage trihexyphenidyl. Neurology 36:160-164. CrossRef Medline

Chiken S, Nambu A (2013) High-frequency pallidal stimulation disrupts information flow through the pallidum by GABAergic inhibition. J Neurosci 33:2268-2280. CrossRef Medline

Clarke NP, Bevan MD, Cozzari C, Hartman BK, Bolam JP (1997) Glutamate-enriched cholinergic synaptic terminals in the entopeduncular nucleus and subthalamic nucleus of the rat. Neuroscience 81:371-385. CrossRef Medline

Cleary DR, Raslan AM, Rubin JE, Bahgat D, Viswanathan A, Heinricher MM, Burchiel KJ (2013) Deep brain stimulation entrains local neuronal firing in human globus pallidus internus. J Neurophysiol 109:978-987. CrossRef Medline

Cole RL, Lechner SM, Williams ME, Prodanovich P, Bleicher L, Varney MA, Gu G (2005) Differential distribution of voltage-gated calcium channel alpha-2 delta (alpha2delta) subunit mRNA-containing cells in the rat central nervous system and the dorsal root ganglia. J Comp Neurol 491: 246-269. CrossRef Medline

Conti MM, Chambers N, Bishop C (2018) A new outlook on cholinergic interneurons in Parkinson's disease and L-DOPA-induced dyskinesia. Neurosci Biobehav Rev 92:67-82. CrossRef Medline

Cubeddu LX, Hoffmann IS (1983) Frequency-dependent release of acetylcholine and dopamine from rabbit striatum: its modulation by dopaminergic receptors. J Neurochem 41:94-101. CrossRef Medline

DeLong MR (1990) Primate models of movement disorders of basal ganglia origin. Trends Neurosci 13:281-285. CrossRef Medline

Dostrovsky JO, Levy R, Wu JP, Hutchison WD, Tasker RR, Lozano AM
(2000) Microstimulation-induced inhibition of neuronal firing in human globus pallidus. J Neurophysiol 84:570-574. CrossRef Medline

Follett KA, Weaver FM, Stern M, Hur K, Harris CL, Luo P, Marks WJ Jr, Rothlind J, Sagher O, Moy C, Pahwa R, Burchiel K, Hogarth P, Lai EC, Duda JE, Holloway K, Samii A, Horn S, Bronstein JM, Stoner G, et al. (2010) Pallidal versus subthalamic deep-brain stimulation for Parkinson's disease. N Engl J Med 362:2077-2091. CrossRef Medline

Hahn PJ, Russo GS, Hashimoto T, Miocinovic S, Xu W, McIntyre CC, Vitek JL (2008) Pallidal burst activity during therapeutic deep brain stimulation. Exp Neurol 211:243-251. CrossRef Medline

Hashimoto T, Elder CM, Okun MS, Patrick SK, Vitek JL (2003) Stimulation of the subthalamic nucleus changes the firing pattern of pallidal neurons. J Neurosci 23:1916-1923. CrossRef Medline

Jiang L, Kundu S, Lederman JD, López-Hernandez GY, Ballinger EC, Wang S, Talmage DA, Role LW (2016) Cholinergic signaling controls conditioned fear behaviors and enhances plasticity of cortical-amygdala circuits. Neuron 90:1057-1070. CrossRef Medline

Kaneda K, Kita H (2005) Synaptically released GABA activates both preand postsynaptic GABA(B) receptors in the rat globus pallidus. J Neurophysiol 94:1104-1114. CrossRef Medline

Kiss ZH, Doig-Beyaert K, Eliasziw M, Tsui J, Haffenden A, Suchowersky O (2007) The canadian multicentre study of deep brain stimulation for cervical dystonia. Brain 130:2879-2886. CrossRef Medline

Kita H (2001) Neostriatal and globus pallidus stimulation induced inhibitory postsynaptic potentials in entopeduncular neurons in rat brain slice preparations. Neuroscience 105:871-879. CrossRef Medline

Kita H, Chiken S, Tachibana Y, Nambu A (2006) Origins of $\mathrm{GABA}_{\mathrm{A}}$ and $\mathrm{GABA}_{\mathrm{B}}$ receptor-mediated responses of globus pallidus induced after stimulation of the putamen in the monkey. J Neurosci 26:6554-6562. CrossRef Medline

Krauss JK, Yianni J, Loher TJ, Aziz TZ (2004) Deep brain stimulation for dystonia. J Clin Neurophysiol 21:18-30. CrossRef Medline

Kringelbach ML, Jenkinson N, Owen SL, Aziz TZ (2007) Translational principles of deep brain stimulation. Nat Rev Neurosci 8:623-635. CrossRef Medline

Krnjević K (2004) Synaptic mechanisms modulated by acetylcholine in cerebral cortex. Prog Brain Res 145:81-93. Medline

Kuo JS, Carpenter MB (1973) Organization of pallidothalamic projections in the rhesus monkey. J Comp Neurol 151:201-236. CrossRef Medline

Lafreniere-Roula M, Kim E, Hutchison WD, Lozano AM, Hodaie M, Dostrovsky JO (2010) High-frequency microstimulation in human globus pallidus and substantia nigra. Exp Brain Res 205:251-261. CrossRef Medline

Langmead CJ, Watson J, Reavill C (2008) Muscarinic acetylcholine receptors as CNS drug targets. Pharmacol Ther 117:232-243. CrossRef Medline

Lavoie B, Parent A (1994) Pedunculopontine nucleus in the squirrel monkey: projections to the basal ganglia as revealed by anterograde tracttracing methods. J Comp Neurol 344:210-231. CrossRef Medline

Lee JR, Kiss ZH (2014) Interhemispheric difference of pallidal local field potential activity in cervical dystonia. J Neurol Neurosurg Psychiatry 85: 306-310. CrossRef Medline

Legéndy CR, Salcman M (1985) Bursts and recurrences of bursts in the spike trains of spontaneously active striate cortex neurons. J Neurophysiol 53: 926-939. CrossRef Medline

Levy R, Dostrovsky JO, Lang AE, Sime E, Hutchison WD, Lozano AM (2001) Effects of apomorphine on subthalamic nucleus and globus pallidus internus neurons in patients with Parkinson's disease. J Neurophysiol 86: 249-260. CrossRef Medline

Li Q, Ke Y, Chan DC, Qian ZM, Yung KK, Ko H, Arbuthnott GW, Yung WH (2012) Therapeutic deep brain stimulation in parkinsonian rats directly influences motor cortex. Neuron 76:1030-1041. CrossRef Medline

Liu LD, Prescott IA, Dostrovsky JO, Hodaie M, Lozano AM, Hutchison WD (2012) Frequency-dependent effects of electrical stimulation in the globus pallidus of dystonia patients. J Neurophysiol 108:5-17. CrossRef Medline

Lobb C (2014) Abnormal bursting as a pathophysiological mechanism in Parkinson's disease. Basal Ganglia 3:187-195. CrossRef Medline

Ludwig A, Flockerzi V, Hofmann F (1997) Regional expression and cellular localization of the $\alpha 1$ and $\beta$ subunit of high voltage-activated calcium channels in rat brain. J Neurosci 17:1339-1349. CrossRef Medline

Luo F, Kiss ZH (2016) Cholinergic mechanisms of high-frequency stimulation in entopeduncular nucleus. J Neurophysiol 115:60-67. CrossRef Medline

Luo F, Yan J (2013) Sound-specific plasticity in the primary auditory cortex 
as induced by the cholinergic pedunculopontine tegmental nucleus. Eur J Neurosci 37:393-399. CrossRef Medline

Luo F, Liu X, Wang C, Yan J (2011) The pedunculopontine tegmental nucleus: a second cholinergic source for frequency-specific auditory plasticity. J Neurophysiol 105:107-116. CrossRef Medline

McCairn KW, Turner RS (2009) Deep brain stimulation of the globus pallidus internus in the parkinsonian primate: local entrainment and suppression of low-frequency oscillations. J Neurophysiol 101:1941-1960. CrossRef Medline

McCairn KW, Iriki A, Isoda M (2015) Common therapeutic mechanisms of pallidal deep brain stimulation for hypo- and hyperkinetic movement disorders. J Neurophysiol 114:2090-2104. CrossRef Medline

McIntyre CC, Grill WM, Sherman DL, Thakor NV (2004) Cellular effects of deep brain stimulation: model-based analysis of activation and inhibition. J Neurophysiol 91:1457-1469. CrossRef Medline

Merello M, Nouzeilles MI, Cammarota A, Betti O, Leiguarda R (1999) Comparison of 1-year follow-up evaluations of patients with indication for pallidotomy who did not undergo surgery versus patients with Parkinson's disease who did undergo pallidotomy: a case control study. Neurosurgery 44:461-467; discussion 467-468. CrossRef Medline

Nakanishi H, Kita H, Kitai ST (1990) Intracellular study of rat entopeduncular nucleus neurons in an in vitro slice preparation: electrical membrane properties. Brain Res 527:81-88. CrossRef Medline

Nambu A (2007) Globus pallidus internal segment. Prog Brain Res 160: 135-150. CrossRef Medline

Nishibayashi H, Ogura M, Kakishita K, Tanaka S, Tachibana Y, Nambu A, Kita H, Itakura T (2011) Cortically evoked responses of human pallidal neurons recorded during stereotactic neurosurgery. Mov Disord 26:469476. CrossRef Medline

Partridge LD, Swandulla D (1988) Calcium-activated non-specific cation channels. Trends Neurosci 11:69-72. CrossRef Medline

Picciotto MR, Higley MJ, Mineur YS (2012) Acetylcholine as a neuromodulator: cholinergic signaling shapes nervous system function and behavior. Neuron 76:116-129. CrossRef Medline

Pisani A, Bernardi G, Ding J, Surmeier DJ (2007) Re-emergence of striatal cholinergic interneurons in movement disorders. Trends Neurosci 30: 545-553. CrossRef Medline

Prescott TJ, Montes González FM, Gurney K, Humphries MD, Redgrave P (2006) A robot model of the basal ganglia: behavior and intrinsic processing. Neural Netw 19:31-61. CrossRef Medline

Quartarone A, Hallett M (2013) Emerging concepts in the physiological basis of dystonia. Mov Disord 28:958-967. CrossRef Medline
Rahman J, Berger T (2011) Persistent activity in layer 5 pyramidal neurons following cholinergic activation of mouse primary cortices. Eur J Neurosci 34:22-30. CrossRef Medline

Ranck JB Jr (1975) Which elements are excited in electrical stimulation of mammalian central nervous system: a review. Brain Res 98:417-440. CrossRef Medline

Rubin JE, Terman D (2004) High frequency stimulation of the subthalamic nucleus eliminates pathological thalamic rhythmicity in a computational model. J Comput Neurosci 16:211-235. CrossRef Medline

Shaltenbrand G, Wahren W (1977) Atlas for stereotaxy of the human brain. Stuttgart: Thieme.

Shin DS, Carlen PL (2008) Enhanced ih depresses rat entopeduncular nucleus neuronal activity from high-frequency stimulation or raised $\mathrm{Ke}+$. J Neurophysiol 99:2203-2219. CrossRef Medline

Shin DS, Samoilova M, Cotic M, Zhang L, Brotchie JM, Carlen PL (2007) High frequency stimulation or elevated $\mathrm{K}+$ depresses neuronal activity in the rat entopeduncular nucleus. Neuroscience 149:68-86. CrossRef Medline

Starr PA, Rau GM, Davis V, Marks WJ Jr, Ostrem JL, Simmons D, Lindsey N, Turner RS (2005) Spontaneous pallidal neuronal activity in human dystonia: comparison with Parkinson's disease and normal macaque. J Neurophysiol 93:3165-3176. CrossRef Medline

Tang JK, Moro E, Mahant N, Hutchison WD, Lang AE, Lozano AM, Dostrovsky JO (2007) Neuronal firing rates and patterns in the globus pallidus internus of patients with cervical dystonia differ from those with Parkinson's disease. J Neurophysiol 98:720-729. CrossRef Medline

Vergara C, Latorre R, Marrion NV, Adelman JP (1998) Calcium-activated potassium channels. Curr Opin Neurobiol 8:321-329. CrossRef Medline

Wess J, Duttaroy A, Zhang W, Gomeza J, Cui Y, Miyakawa T, Bymaster FP, McKinzie L, Felder CC, Lamping KG, Faraci FM, Deng C, Yamada M (2003) M1-M5 muscarinic receptor knockout mice as novel tools to study the physiological roles of the muscarinic cholinergic system. Receptors Channels 9:279-290. CrossRef Medline

Woolf NJ, Butcher LL (1986) Cholinergic systems in the rat brain: III. Projections from the pontomesencephalic tegmentum to the thalamus, tectum, basal ganglia, and basal forebrain. Brain Res Bull 16:603-637. CrossRef Medline

Zhang J, Wang ZI, Baker KB, Vitek JL (2012) Effect of globus pallidus internus stimulation on neuronal activity in the pedunculopontine tegmental nucleus in the primate model of Parkinson's disease. Exp Neurol 233:575580. CrossRef Medline 